ARTICLE

\title{
Chiral gold nanoparticles enantioselectively rescue memory deficits in a mouse model of Alzheimer's disease
}

Ke Hou ${ }^{1,2,3}$, Jing Zhao ${ }^{4}$, Hui Wang ${ }^{1}$, Bin $\mathrm{Li}^{1,5}$, Kexin $\mathrm{Li}^{6}$, Xinghua Shi (10 ${ }^{1}$, Kaiwei Wan (1) ${ }^{1}$, Jing Ai ${ }^{6}$, Jiawei Lv', Dawei Wang ${ }^{1}$, Qunxing Huang ${ }^{1}$, Huayi Wang${ }^{1}$, Qin Cao ${ }^{7}$, Shaogin Liu ${ }^{4 凶}$ \& Zhiyong Tang $\mathbb{B}^{1,3 凶}$

Preventing aggregation of amyloid beta $(A \beta)$ peptides is a promising strategy for the treatment of Alzheimer's disease (AD), and gold nanoparticles have previously been explored as a potential anti-A $\beta$ therapeutics. Here we design and prepare $3.3 \mathrm{~nm} \mathrm{L-}$ and D-glutathione stabilized gold nanoparticles (denoted as L3.3 and D3.3, respectively). Both chiral nanoparticles are able to inhibit aggregation of $A \beta 42$ and cross the blood-brain barrier (BBB) following intravenous administration without noticeable toxicity. D3.3 possesses a larger binding affinity to $A \beta 42$ and higher brain biodistribution compared with its enantiomer L3.3, giving rise to stronger inhibition of $A \beta 42$ fibrillation and better rescue of behavioral impairments in $A D$ model mice. This conjugation of a small nanoparticle with chiral recognition moiety provides a potential therapeutic approach for AD.

\footnotetext{
${ }^{1}$ CAS Key Laboratory of Nanosystem and Hierarchical Fabrication, CAS Center for Excellence in Nanoscience, National Center for Nanoscience and Technology, Beijing 100190, China. ${ }^{2}$ Center for Nanochemistry, Peking University, Beijing 100871, China. ${ }^{3}$ University of Chinese Academy of Sciences, Beijing 100049, China. ${ }^{4}$ MOE Key Laboratory of Micro-systems and Micro-structures Manufacturing, School of Life Science and Technology, Harbin Institute of Technology, Harbin 150001, China. ${ }^{5}$ School of Chemical Engineering and Technology, Sun Yat-sen University, Zhuhai 519082, China. ${ }^{6}$ Department of Pharmacology, the State-Province Key Laboratories of Biomedicine-Pharmaceutics of China, College of Pharmacy of Harbin Medical University, Harbin 150086, China. ${ }^{7}$ Department of Chemistry and Biochemistry and Biological Chemistry, UCLA-DOE Institute and Howard Hughes Medical Institute, UCLA,

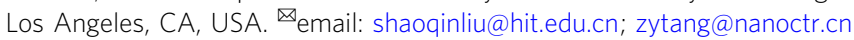


A lzheimer's disease $(\mathrm{AD})$, clinically characterized by progressive attrition of memory and other cognitive ability, is the most prevalent form of neurodegenerative diseases that affects 50 million people and costs US\$ 1 trillion in $2018^{1}$. Generally, AD pathology involves proteinopathy of intra- or extracellular misfolded protein/peptide aggregates ${ }^{2}$, metal ion dyshomeostasis $^{3}$, oxidative stress caused by reactive oxygen species $^{4}$, and loss of cholinergic transmission ${ }^{5}$. Increasing evidence indicate that deposition of neurofibrillary tangles and senile plaques, respectively composed of misfolded aggregates of intracellular microtubule-associated tau proteins and extracellular amyloid- $\beta$ (A $\beta)$ peptides, is two prominent histopathological features of $\mathrm{AD}^{6}$. Accordingly, targeting production, aggregation, and clearance of $\mathrm{A} \beta$ or tau from the brain is a mainstream measure for preventing or curing $\mathrm{AD}^{7}$. A wide variety of small molecules $^{8}$ and peptides ${ }^{9}$ capable of inhibiting $A \beta$ oligomerization or fibrillogenesis have been examined, and some improvements have been observed ${ }^{7}$. Unfortunately, many compounds enter into clinical trials but with moderate-to-poor success rate ${ }^{10}$. These failures originate from bad inhibition efficiency, low blood-brain barrier (BBB) permeability, unfavorable biocompatibility, and adverse effects, etc ${ }^{11}$.

Alternatively, recent studies have demonstrated that some nanoparticles (NPs) could accelerate or retard A $\beta$ aggregation process and thus be expected as potential drugs against $\mathrm{AD}^{12-15}$. The binding affinity and anti-amyloid capacity of NPs are tuned by controlling their physiochemical properties, such as size ${ }^{12}$, shape $^{13}$, surface charge ${ }^{14}$, and hydrophobicity ${ }^{15}$. Conjugation of NPs with peptides- and small molecule-based inhibitors further enhances their inhibition efficiency toward $A \beta^{16,17}$. Among various NPs, gold $(\mathrm{Au}) \mathrm{NPs}$ are believed as practical nanochaperones to inhibit and redirect $A \beta$ fibrillization ${ }^{14}$, owing to their good biocompatibility, easy functionalization ${ }^{18}$, and potential ability to cross $\mathrm{BBB}^{19}$. However, by far the inhibition efficiency of the reported Au NP systems is much worse compared with small molecule- and peptide-based inhibitors ${ }^{14}$. Although grafting the peptides onto Au NPs might improve the inhibition activity against $\mathrm{A} \beta$ aggregations ${ }^{20}$, their $\mathrm{BBB}$ permeability and in vivo efficacy remain unexplored.

In this work, chiral L- and D-glutathione (GSH) stabilized Au NPs with diameters of $3.3 \mathrm{~nm}$, which are named as L3.3 and D3.3, are rationally designed. As a tripeptide antioxidant, GSH is known to protect tissues from damage caused by reactive oxygen species, and thus possesses the therapeutic potential in $\mathrm{AD}^{21}$ and other neurodegenerative diseases ${ }^{22}$. In addition, due to the high level of GSH transporters located in the brain, surface capping with GSH enables Au NPs to permeate the $\mathrm{BBB}^{23}$. Most importantly, the surface chirality ${ }^{24}$ and helix structure ${ }^{25}$ can enantioselectively prevent $A \beta$ aggregation in vitro. Therefore, the introduction of chiral GSH ligand is expected to endow gold NPs the exceptional ability toward chiral recognition of $A \beta$ and enantioselective inhibition of $A \beta$ fibrillation. Furthermore, $A u$ NPs that function as the carriers will provide the unique opportunity for optimizing BBB permeability and in vivo efficacy via altering their size or shape.

\section{Results}

Inhibitory effect on A $\boldsymbol{\beta} 42$ aggregation in vitro. Previous studies have demonstrated that the size of NPs exerts a large influence on $\mathrm{A} \beta$ aggregation ${ }^{26}$ and such size-dependent phenomenon is likely associated with the curvature of $\mathrm{NPs}^{27}$. Thus, Monte Carlo simulation was first adopted to investigate the self-assembly behavior of peptide chains on different sized $\mathrm{Au} \mathrm{NPs}^{28}$ (see the details in Supplementary Method, Supplementary Fig. 1, and Supplementary Table 1). Interestingly enough, the presence of $\mathrm{Au}$
NPs would considerably decrease the average number of peptide chains in the formed aggregates, and the NPs with the size of 3-4 $\mathrm{nm}$ exhibit the best inhibition performance. So we intend to choose $3.3 \mathrm{~nm} \mathrm{Au} \mathrm{NPs} \mathrm{including} \mathrm{L3.3} \mathrm{and} \mathrm{D3.3} \mathrm{as} \mathrm{the} \mathrm{main}$ investigated candidates ${ }^{29}$. As the contrast samples for inhibiting $\mathrm{A} \beta$ fibrillation, $9 \mathrm{~nm}$ and $15 \mathrm{~nm} \mathrm{L-}$ or D-GSH-coated Au NPs (abbreviated as L9, D9, L15, and D15, respectively) are prepared for verifying the size effect ${ }^{30}$ (Supplementary Figs. 2-4 and Supplementary Table 2). In addition, $3.5 \mathrm{~nm}$ non-chiral citratecoated $\mathrm{Au}$ NPs (abbreviated as C3.5) are synthesized for investigating the enantioselective impact ${ }^{31}$ (Supplementary Fig. 5). $\mathrm{A} \beta 42$ that has the largest $\mathrm{AD}$ toxicity among different $\mathrm{A} \beta$ peptides is selected for in vitro study ${ }^{32}$.

The Thioflavin $\mathrm{T}$ (ThT) fluorescence assay was employed to inspect the inhibitory effect of different Au NPs on A $\beta 42$ fibrillation. In the experiments, the concentration of various $\mathrm{Au}$ NPs is adjusted to have the same surface areas (Supplementary Table 3). When fresh $\mathrm{A} \beta 42$ alone is incubated at $37^{\circ} \mathrm{C}$ (Supplementary Fig. 6), ThT fluorescence presents a sigmoidal shape as a function of incubation time (black curve in Fig. 1a), following the classic nucleation-growth process ${ }^{15}$. Remarkably, when incubating L3.3 or D3.3 with $\mathrm{A} \beta 42$ solution, a strong inhibition effect on $A \beta 42$ fibrillization is discerned, as evidenced by a $60 \%$ or $63 \%$ decrease in the maximum ThT intensity compared with pure A $\beta 42$ (magenta and blue curves in Fig. 1a). Also, $9 \mathrm{~nm}$ and $15 \mathrm{~nm}$ L- or D-GSH-coated Au NPs apparently inhibit $\mathrm{A} \beta 42$ fibrillization, in which the maximum ThT intensity decreases by $36 \%$ (L9), 58\% (D9), 27\% (L15), and 51\% (D15), respectively (Supplementary Fig. 7a). To be more accurate, the lag time, the time required to reach half of the maximum fluorescence intensity $t_{1 / 2}$ and apparent aggregation constant $k$ are obtained by fitting ThT data with sigmoidal curves (Supplementary Table 4) ${ }^{15}$. It is clear that the chiral Au NPs exhibit an inhibition effect on $A \beta 42$ aggregation by increasing the lag time and reducing the rate of $\mathrm{A} \beta 42$ aggregation. It deserves to be stressed that free L- or D-GSH molecules show negligible inhibition effect on $A \beta 42$ fibrillization due to their weaker interaction with $A \beta 42$ in solution ${ }^{33}$ (Supplementary Fig. 8); while addition of $\mathrm{C} 3.5$ results in only $11 \%$ decrease in the maximum ThT intensity, indicating that C3.5 has very weak inhibitory effect like GSH molecules (green curve in Fig. 1a and Supplementary Table 4). Because the fluorescence quenching of ThT caused by $\mathrm{Au}$ NPs can be ignored under the experimental condition ${ }^{12}$ (Supplementary Fig. 9), it is deduced that the introduction of chiral GSH stabilized $\mathrm{Au}$ NPs dramatically enhances the inhibition activity on $\mathrm{A} \beta 42$ fibrillization.

The influence of Au NPs on the conformational transition of A $\beta 42$ was assessed using circular dichroism (CD) spectroscopy. As a control, $A \beta 42$ aggregation leads to the formation of $\beta$ sheetrich framework with a typical positive CD peak at $195 \mathrm{~nm}$ and a negative minimum at $215 \mathrm{~nm}$ (black curve in Fig. 1b). All Au NPs might prevent the structural transition of $A \beta 42$ from native random coil to $\beta$-sheet conformation in solution (Fig. $1 \mathrm{~b}$ and Supplementary Fig. 7b), which is quantitatively estimated according to the previous report ${ }^{34}$. The $\mathrm{A} \beta 42$ fibrils contain $48.3 \pm 3.0 \%$ of $\beta$-sheet structure, which reduces to $45.2 \pm 3.4 \%$, $43.2 \pm 0.4 \%, 29.3 \pm 2.1 \%, 47.4 \pm 2.2 \%, 37.3 \pm 0.5 \%, 47.4 \pm 0.4 \%$, and $42.2 \pm 2.0 \%$ upon incubation with C3.5, L3.3, D3.3, L9, D9, $\mathrm{L} 15$, and D15, respectively. Correspondingly, the percentage of the random coil structures increases (Fig. 1c and Supplementary Fig. 7c).

Besides the conformational transition, the effect of Au NPs on the morphology change of $A \beta 42$ aggregates is observed by atomic force microscopy (AFM) and transmission electron microscopy (TEM) imaging (Fig. 1d, e and Supplementary Fig. 7d, e). Typical non-branched amyloid fibrils with lengths of up to several 

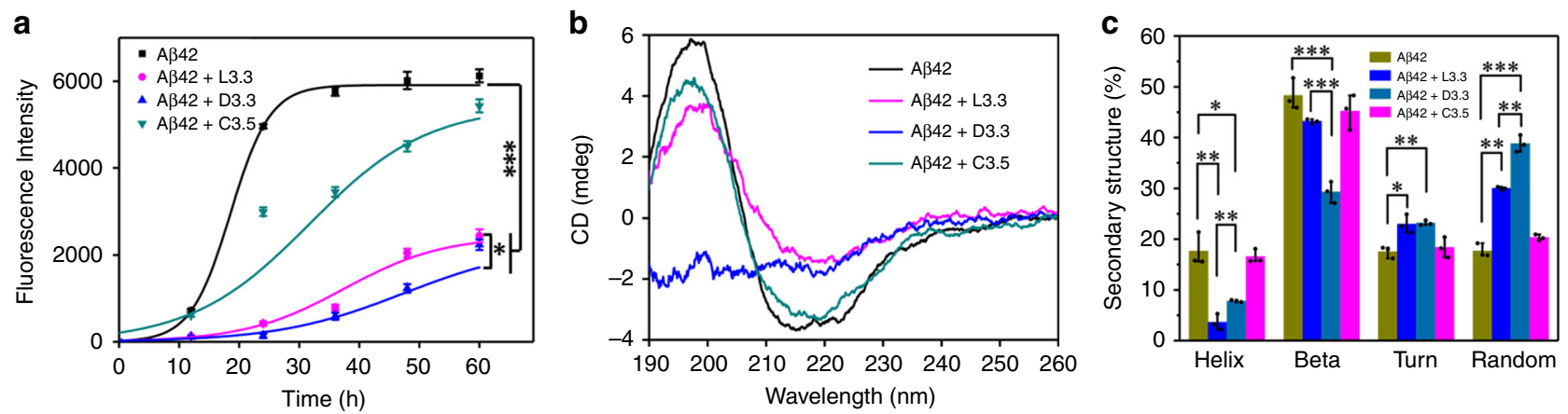

d $\mathrm{A} \beta 42$

$A \beta 42+L 3.3$
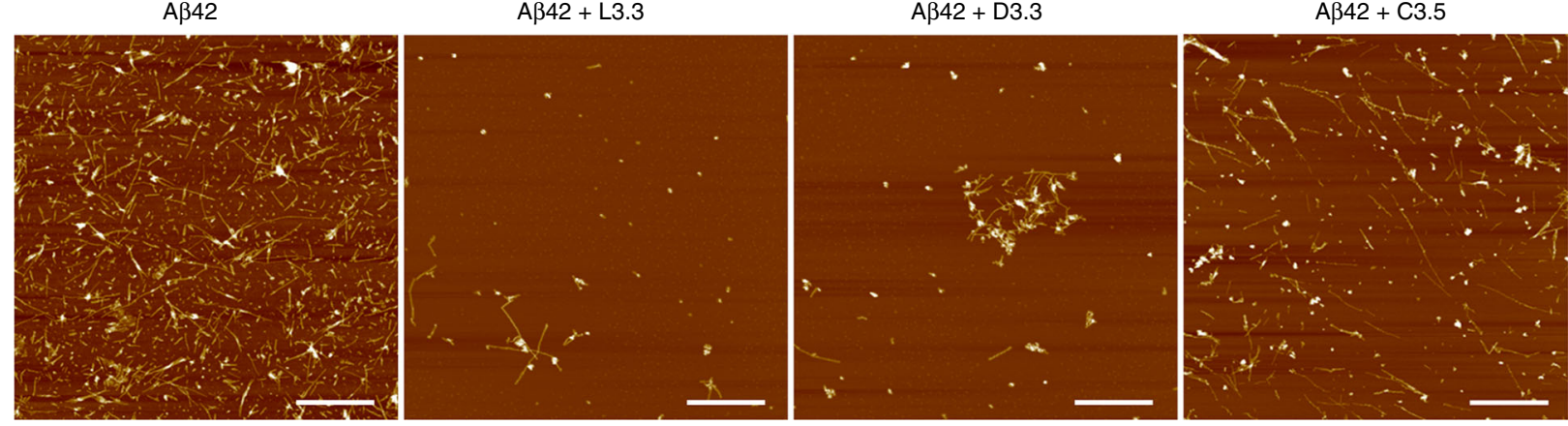

$\mathbf{e}$ $\mathrm{A} \beta 42$ $A \beta 42+L 3.3$
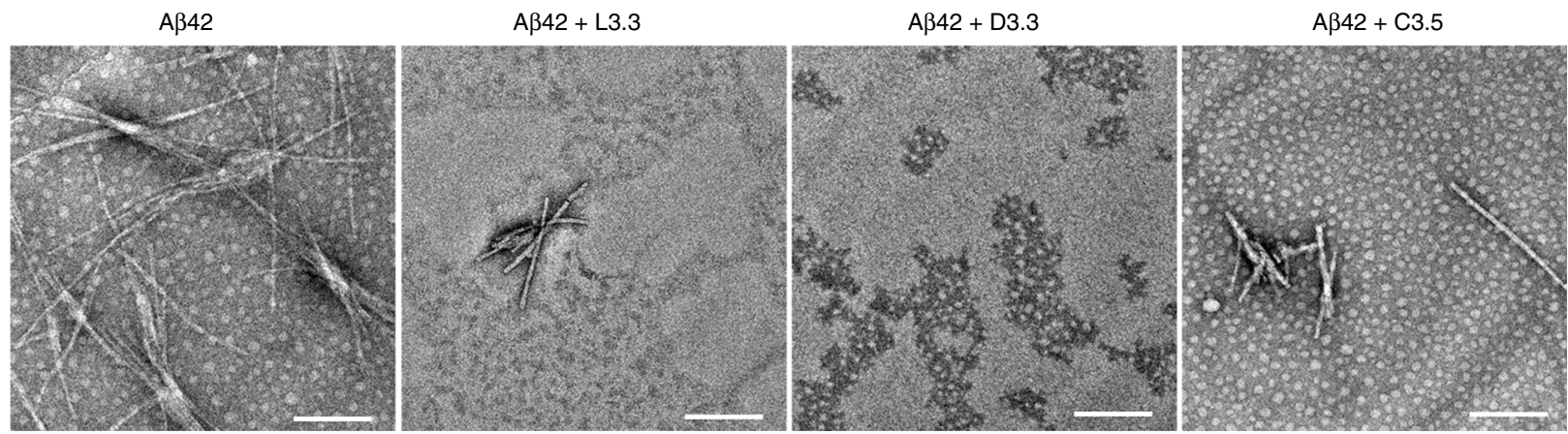

Fig. 1 Effect of L3.3, D3.3, and C3.5 on A $\mathbf{A} 42$ fibrillization in vitro. a ThT fluorescence assay of A 342 in the absence and presence of $3.3-n m$ L-GSH capped Au nanoparticles (denoted as A $342+$ L3.3), $3.3 \mathrm{~nm}$ D-GSH capped Au nanoparticles (abbreviated as A $342+$ D3.3), or 3.5 nm citrate-capped Au nanoparticles (denoted as $A \beta 42+C 3.5$ ). The fibrillation kinetics is fitted with a sigmoidal function. $\mathbf{b} C D$ spectra of $A \beta 42$ ( $40 \mu M$ ) in the absence and presence of $\mathrm{L3} 3$ 3, D3.3, or C3.5 (110 $\mathrm{nM}$ ) after co-incubation for $48 \mathrm{~h}$. c Analysis of protein secondary structure. d AFM images of $\mathrm{A} \beta 42$ ( $40 \mu \mathrm{M}$ ) in the absence and presence of L3.3, D3.3, or C3.5 (110 nM) after co-incubation for $48 \mathrm{~h}$. Scale bars, $1 \mu \mathrm{m}$. e TEM images of $\mathrm{A} \beta 42$ ( $40 \mu \mathrm{M}$ ) in the absence and presence of L3.3, D3.3, or C3.5 (110 nM) after co-incubation for 48 h. Scale bars, 200 nm. Error bars indicate the s.d. ( $n=3$ independent samples). ${ }^{\star} P<$ $0.05,{ }^{\star \star} P<0.01,{ }^{\star \star \star} P<0.001$, two-sided Student's $t$ test. For detailed statistical analysis see Supplementary Tables 6 and 7 . Source data are provided as a Source Data file.

micrometers are found in the sample of pure $A \beta 42^{35}$. When incubating $A \beta 42$ with various Au NPs, the length of the $A \beta 42$ fibrils becomes shorter. Particularly, in the presence of D3.3, the mature amyloid fibrils are seldom discerned, and numerous small and relatively amorphous aggregates are distinguished, demonstrating their excellent efficacy on inhibiting A $\beta 42$ fibrillization.

After validating the effectiveness of chiral Au NPs on inhibition of $\mathrm{A} \beta 42$ fibrillization, their size effect is studied by analyzing the CD spectra and ThT fluorescence assay (Supplementary Figs. 10 and 11). Regardless of L-GSH or D-GSH used as the surface stabilizers, $3.3 \mathrm{~nm}$ Au NPs display the best inhibition efficiency, confirmed by increasing the lag time and reducing the rate of $A \beta 42$ aggregation ${ }^{15}$. This result is well consistent with the above simulation about the dependence of peptide aggregate structure on Au NP size (Supplementary Fig. 1 and Supplementary Table 1).
The surface chirality of GSH-coated Au NPs also strongly influences their inhibitory activity. D3.3 exerts a greater inhibitory effect on amyloid fibril formation than L3.3 (Fig. 1), and a similar phenomenon is recognized for $9 \mathrm{~nm}$ and $15 \mathrm{~nm}$ GSH-coated Au NPs (Supplementary Fig. 7). To reveal the origin of the difference in the performance of L3.3 and D3.3 on preventing $A \beta 42$ aggregation, the binding constant between $A \beta 42$ and L3.3 or D3.3 is measured with isothermal titration calorimetry (ITC) ${ }^{36}$ (Fig. 2a, b). As displayed in Fig. 2c, the favorable enthalpy change $(\Delta H<0)$ and unfavorable entropy loss $(\Delta S<0)$ suggest that the complexation between A $\beta 42$ and L3.3 or D3.3 is partly dominated by hydrogen bond and electrostatic interaction ${ }^{37}$. In addition, the fitted binding stoichiometry $\left(n_{0}\right)$ implies that A $\beta 42$ multilayers are formed on the surfaces of both L3.3 and D3.3 37 . The binding constant $K$ between A $\beta 42$ and D3.3 is $\sim 2.5$ times larger than that between $\beta 42$ and L3.3. Furthermore, 
a

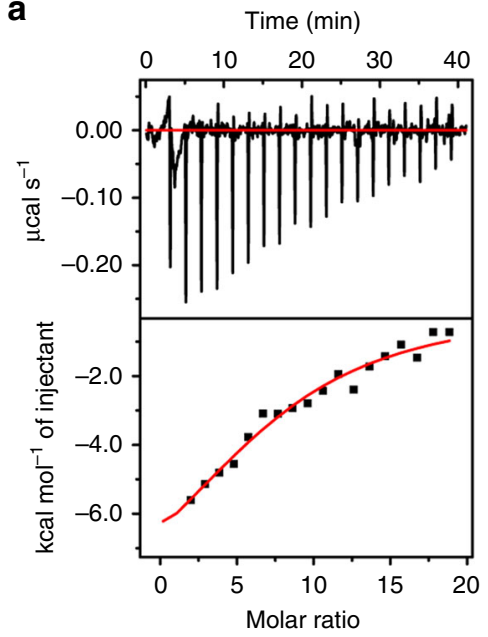

b

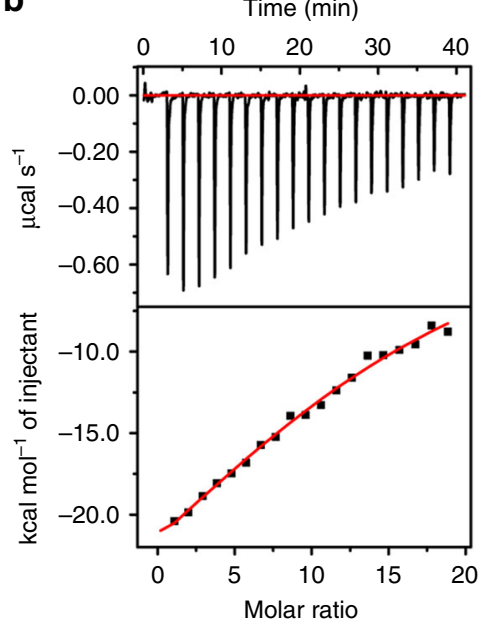

d

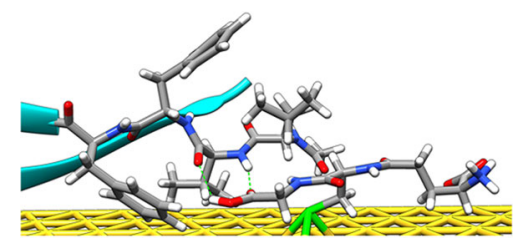

e

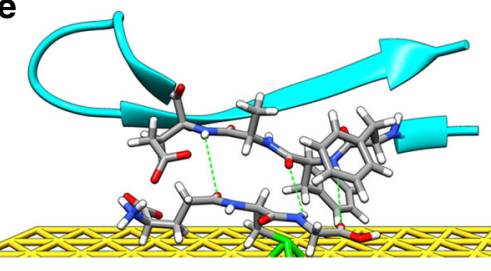

c

\begin{tabular}{cccccc}
\hline Sample & $n_{0}$ & $\begin{array}{c}10^{-5} \mathrm{~K} \\
\left(\mathrm{M}^{-1}\right)\end{array}$ & $\begin{array}{c}\Delta H \\
\left.(\mathrm{kcal} \mathrm{mol})^{-1}\right)\end{array}$ & $\begin{array}{c}\Delta S \\
\left(\mathrm{cal} \mathrm{mol}^{-1} \mathrm{~K}^{-1}\right)\end{array}$ & $\begin{array}{c}\Delta G^{*} \\
\left(\mathrm{kcal} \mathrm{mol}^{-1}\right)\end{array}$ \\
\hline L3.3 & $6.7 \pm 0.9$ & $1.0 \pm 0.3$ & $-31.3 \pm 18.4$ & $-98.0 \pm 35.4$ & $-6.7 \pm 0.2$ \\
D3.3 & $10.7 \pm 5.4$ & $2.6 \pm 1.4$ & $-32.8 \pm 10.8$ & $-85.5 \pm 36.7$ & $-7.3 \pm 0.2$ \\
\hline
\end{tabular}

Fig. 2 Analysis of interaction between L3.3/D3.3 and Aß42 monomer. a, b Typical ITC data for titration of A 342 (0.138 mM) into solution of L3.3 (1.5 $\mu \mathrm{M})(\mathbf{a})$ and D3.3 $(1.5 \mu \mathrm{M})(\mathbf{b})$ at $25^{\circ} \mathrm{C}$. (Upper) raw data and (lower) integrated data. The solid curves represent the best-fit results using a one-site binding model. The experiment was repeated for three times. c Summary of binding stoichiometry $n_{0}$, binding constant $K$, enthalpy changes $\Delta H$, entropy changes $\Delta S$, and Gibbs free energy changes $\Delta G$ of binding process of $A \beta 42$ monomer on L3.3 (a) and D3.3 (b). Error bars indicate mean \pm s.d. ${ }^{\star} P<0.05$, two-sided Student's $t$ test. For detailed statistical analysis see Supplementary Table 7. d, e The most stable structures of A $\beta 17-36$ with L- (d) and D-GSHcoated Au (111) surface (e) obtained from molecular docking simulation (atom color: C, gray; H, white; N, blue; O, red; S, green; Au, yellow). Green dotted lines represent hydrogen bonding. Source data are provided as a Source Data file.

the Gibbs free energy change $\Delta G$ of binding process of $A \beta 42$ monomer on D3.3 is significantly lower than that on L3.3 $\left(-7.3 \pm 0.2\right.$ vs. $\left.-6.7 \pm 0.2 \mathrm{kcal} \mathrm{mol}^{-1}, * P<0.05\right)$, indicating the binding process of $\mathrm{A} \beta 42$ with $\mathrm{D} 3.3$ is more energetically favorable. Hence, the strong affinity between D3.3 and A $\beta 42$ monomer would substantially lower the concentration of free $\mathrm{A} \beta 42$ monomers, shift the equilibrium away from $\mathrm{A} \beta 42$ aggregation, and thus hinder fibril growth ${ }^{36}$.

The theoretical simulation was further conducted to elucidate the binding mode of $\mathrm{A} \beta$ peptides onto the surfaces of $\mathrm{L} 3.3$ or D3.3. Based on Supplementary Fig. 12a model of Au (111) layers decorated with one L- or D-GSH molecule via $\mathrm{Au}-\mathrm{S}$ bond is adopted to represent L3.3/D3.3. Moreover, to simplify the calculation, the $A \beta 17-36$ fragment is used to mimic $A \beta 42$ because it has a similar "beta-turn-beta" structure and assembly behavior (Supplementary Fig. 13a) ${ }^{38}$. The L- or D-GSH stabilized Au (111) layers are optimized through density functional theory (DFT) calculation $^{39-41}$ (Supplementary Fig. 13b, c), which are subsequently docked with $\mathrm{A} \beta 17-36$ peptide to figure out the most stable binding conformation ${ }^{42}$ (Fig. 2d, e and Supplementary Fig. 13d, e). The corresponding binding free energy of $A \beta 17-36$ with D-GSH stabilized Au (111) layer is $-4.64 \mathrm{kcal} \mathrm{mol}^{-1}$, larger than that with L-GSH stabilized Au (111) layer $\left(-4.19 \mathrm{kcal} \mathrm{mol}^{-1}\right)$, confirming that D3.3 has stronger interaction with $\mathrm{A} \beta$ than L3.3. This simulation result is consistent with binding constant measurement (Fig. 2c) and inhibition activity observation (Fig. 1a). Most importantly, as demonstrated in Fig. 2d, e, the L- or D-GSH on $\mathrm{Au}$ (111) layers prefer interacting with the KLVFFA segment of $A \beta$ via hydrogen bonding, which is the widely accepted key element for forming $\mathrm{A} \beta$ aggregation ${ }^{43}$. This result reveals why
D3.3 and L3.3 possess a good target capability to prevent $A \beta$ aggregation.

Inhibition effect on $\mathbf{A} \boldsymbol{\beta}$-mediated cellular toxicity. The ability of L3.3 or D3.3 to inhibit $A \beta 42$ aggregation holds the promise of protecting cells from $A \beta$-mediated toxicity. So, the Cell Counting Kit-8 (CCK-8) assay was performed to probe the cell viability of human neuroblastoma cell line SH-SY5Y. As a control, CCK-8 assay is carried out with $25-500 \mathrm{nM}$ of L3.3 or D3.3, and the result displays that both L3.3 and D3.3 have almost no cytotoxicity to cells, indicated by $>80 \%$ cell viability (Supplementary Fig. 14a). On the contrary, pure $\mathrm{A} \beta 42$ is quite toxic to the $\mathrm{SH}-$ SY5Y cells, leading to $<45 \%$ cell viability (Fig. $3 a$ ). When L3.3 or D3.3 is added to $A \beta 42$, SH-SY5Y cells are saved from $A \beta$ mediated toxicity. Especially, D3.3 improves the cellular viability of up to $80 \%$ while L3.3 achieves survival of $72 \%$.

Moreover, terminal transferase dUTP nick end labeling (TUNEL) assay was conducted to detect cell apoptosis. The normal cell nuclei appear blue while the apoptotic cell nuclei show green with TUNEL-4',6-diamidino-2-phenylindole (DAPI) co-staining (Fig. 3b). The D3.3 treatment causes a more obvious decrease in SH-SY5Y cell apoptosis than L3.3. To quantify cell apoptosis, SH-SY5Y cells treated with $\mathrm{A} \beta 42$ plus D3.3 (or A $\beta 42$ plus L3.3) for $48 \mathrm{~h}$ were stained with annexin V-fluorescein isothiocyanate (Annexin V-FITC)/propidium iodide (PI; Supplementary Fig. 14b). Compared with pure $A \beta 42$, incubation of $\mathrm{A} \beta 42$ with L3.3 or D3.3 gives rise to a decrease of apoptosis from $42.9 \%$ to $36.2 \%$ or $32.1 \%$ (Fig. 3 c, d). Altogether, both L3.3 and D3.3 can protect SH-SY5Y neuronal cells from cytotoxicity induced by $\mathrm{A} \beta 42$ aggregation, and $\mathrm{D} 3.3$ has a more significant 
a

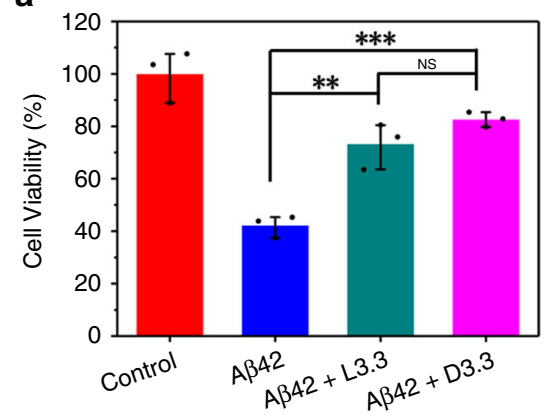

C

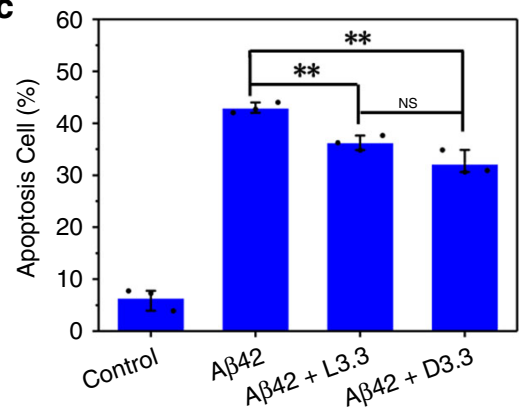

b

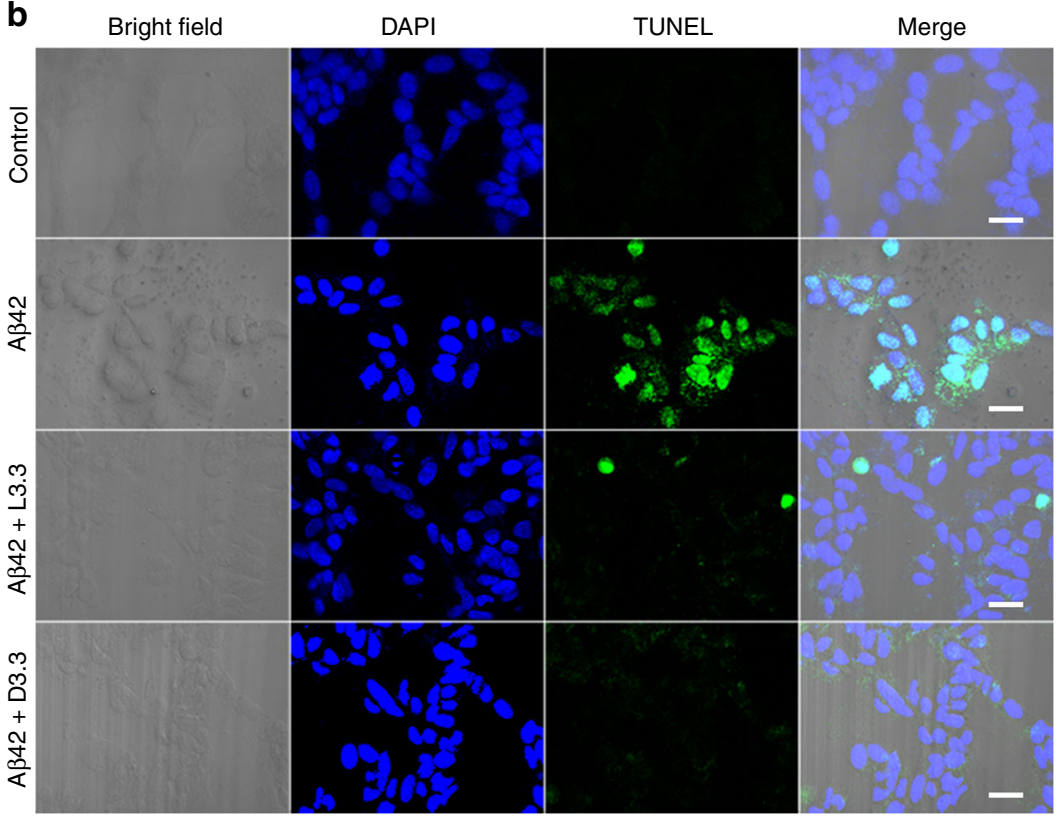

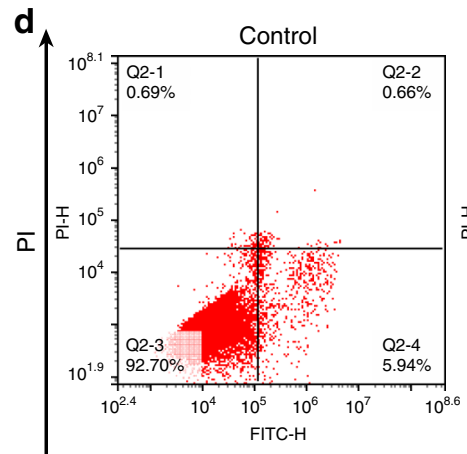
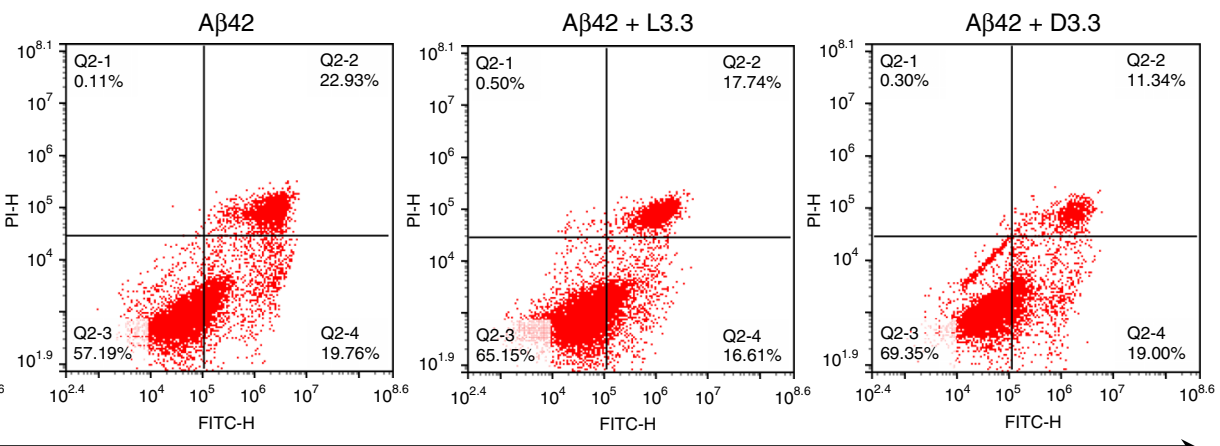

Annexin V-FITC

Fig. 3 Inhibition effect of $\mathbf{L} 3.3$ and D3.3 on A $\mathbf{A 4 2}$-induced neuronal death. a Cell toxicity of $A \beta 42(40 \mu M)$ in the absence and presence of L3.3 and D3.3 $(110 \mathrm{nM})$. b Bright-field and confocal fluorescence images of SH-SY5Y cells treated with A $342(40 \mu \mathrm{M})$ in the absence and presence of L3.3 and D3.3 (110 $\mathrm{nM}$ ) for $48 \mathrm{~h}$. Scale bars, $50 \mu \mathrm{m}$. c Population of apoptosis cells summarized from flow cytometry analysis. $\mathbf{d}$ Flow cytogram representing apoptosis assay based on annexin $\mathrm{V}$-fluorescein isothiocyanate (Annexin V-FITC)/propidium iodide (PI) staining of SH-SY5Y cells after treatment with different therapeutic groups for $48 \mathrm{~h}$. Error bars indicate the s.d. ( $n=3$ independent samples). ${ }^{\star \star} P<0.01$; ${ }^{\star \star \star} P<0.001$; NS not significant; one-way ANOVA, followed by Holm-Sidak post hoc test. For detailed statistical analysis see Supplementary Tables 6 and 7 . Source data are provided as a Source Data file.

effect in reducing the apoptosis rate due to its stronger interaction with $\mathrm{A} \beta 42$ and higher inhibition ability.

Biodistribution and toxicity evaluation in vivo. The therapeutic efficacy of L3.3 and D3.3 for AD strongly depends on their blood circulation time and ability to override the BBB. Previous study has demonstrated that there is high level of GSH transporters located in the brain ${ }^{23}$, so it is expected that chiral GSH coating enables $\mathrm{Au}$ NPs of small sizes possessing more efficient BBB permeability. L3.3 or D3.3 (25 $\left.\mathrm{mg} \mathrm{kg}^{-1}\right)$ was injected intravenously into healthy Kun Ming (KM) mice, and their biodistribution was determined by measuring the amount of $\mathrm{Au}$ element through inductively coupled plasma mass spectrometry (Fig. 4a, b and Supplementary Fig. 15). As summarized in Fig. 4a, the amount of $\mathrm{Au}$ in the brain of L3.3- or D3.3-injected mice reaches the maximum concentration (10 times higher than that of the control group) at $12 \mathrm{~h}$ or $6 \mathrm{~h}$, respectively. This result discloses that L3.3 and D3.3 could be transported from the blood circulation into brain. Notably, the surface chirality of $\mathrm{Au}$ NPs significantly influences the biodistribution of D3.3 and L3.3 in the brain at first $6 \mathrm{~h}$, implying that L3.3 and D3.3 may cross the BBB through transporter proteins ${ }^{44}$ besides spontaneous penetration ${ }^{19,45}$. Moreover, the Au content begins to decrease after $12 \mathrm{~h}$ for L3.3-injected mice and $24 \mathrm{~h}$ for D3.3-injected mice, respectively, suggesting that the clearance of D3.3 from the brain is slower than that of L3.3. As expected, the amount of L3.3 and D3.3 in the blood gradually decreases with the prolonged time because of clearance and aggregation (Fig. 4b). The clearance of L3.3 and D3.3 in plasma follows the first-order elimination kinetics (Fig. 4c). The half-life of L3.3 and D3.3 is $14.3 \mathrm{~h}$ and 14.8 $\mathrm{h}$, respectively, which is close to the reported values of other $\mathrm{Au}$ $\mathrm{NPs}^{45}$.

To evaluate the biosafety of L3.3 and D3.3 for AD treatments, serum biochemistry assay and hematoxylin and eosin (H\&E) staining of major organs were performed. The results display that the hematological parameters first suffer slight fluctuation at the early stage of injection ( $6 \mathrm{~h}$ and $12 \mathrm{~h}$ ), then recover to the normal range (from $24 \mathrm{~h}$ to $48 \mathrm{~h}$; Fig. $4 \mathrm{~d}$ and Supplementary Fig. 16). The histological section of heart, liver, spleen, lung, and kidney with 
a

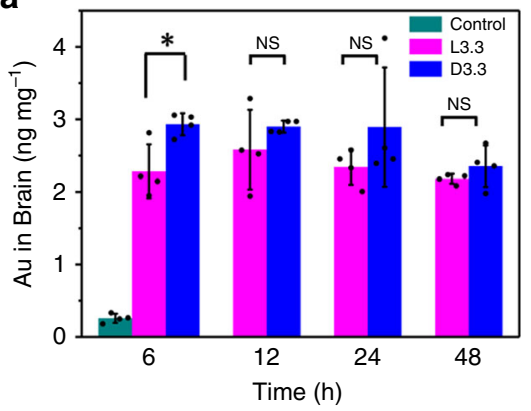

b

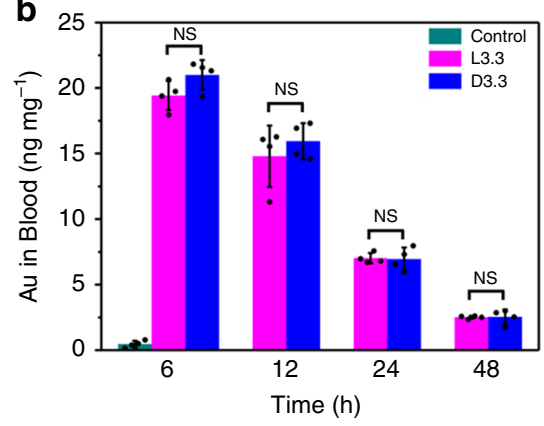

C

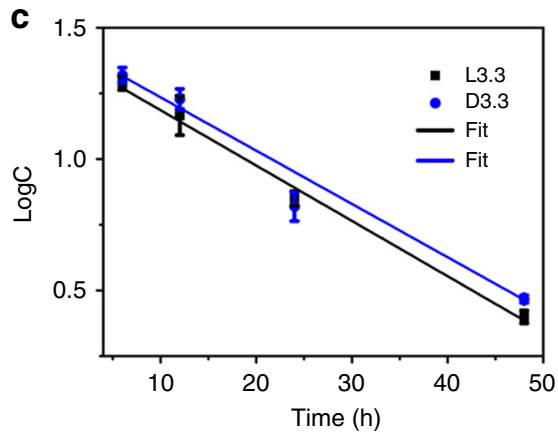

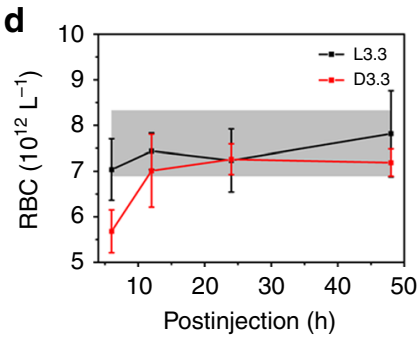
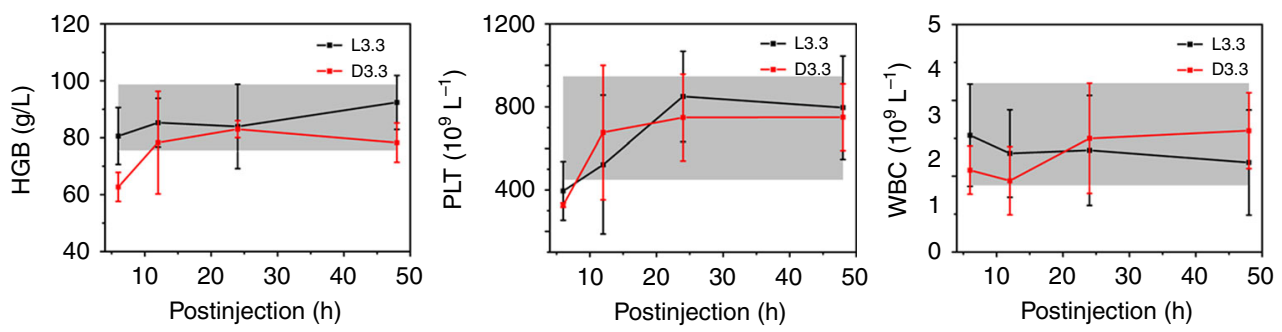

e
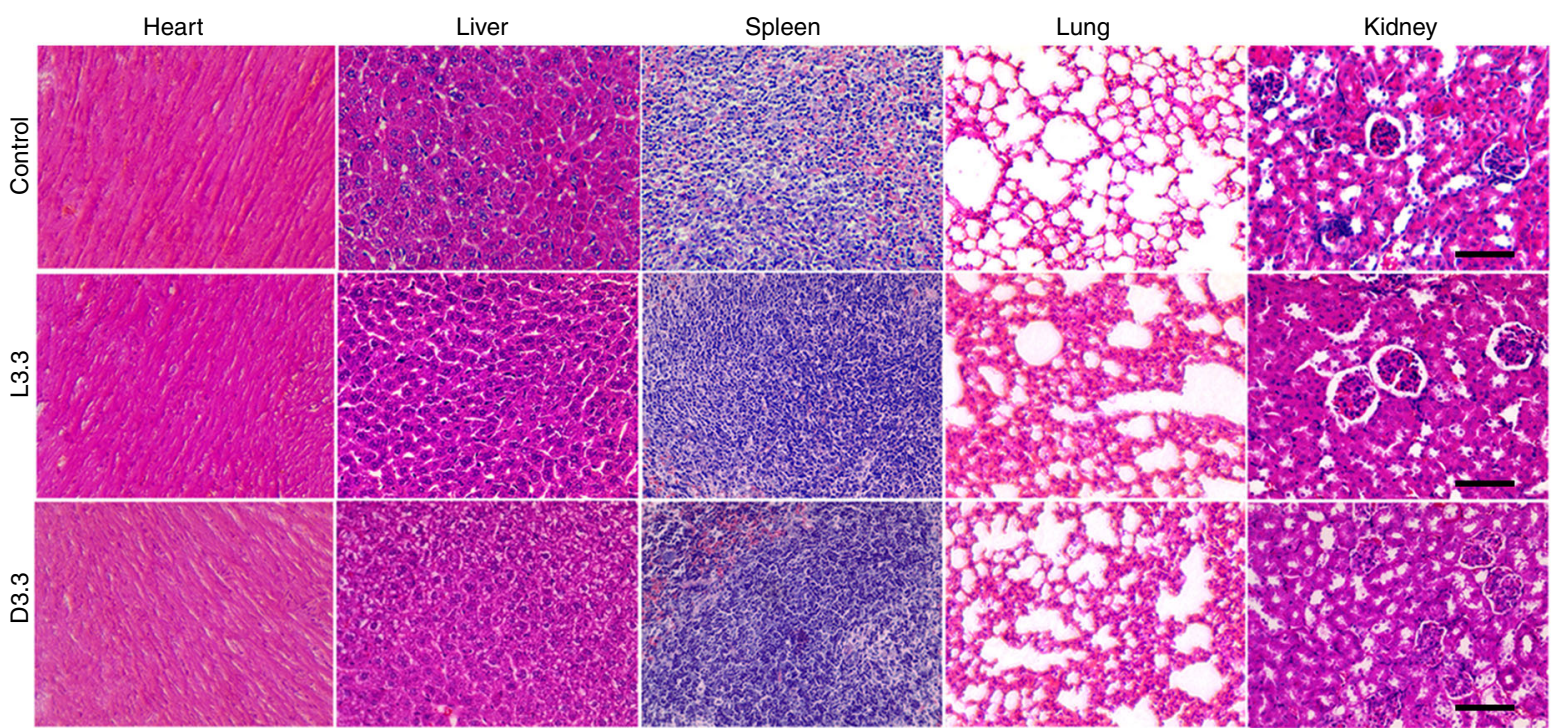

Fig. 4 Biodistribution and toxicity evaluation of L3.3 and D3.3 in vivo. a, b Biodistribution of L3.3 and D3.3 in the brain (a) and blood (b) at $6 \mathrm{~h}, 12 \mathrm{~h}, 24 \mathrm{~h}$, and $48 \mathrm{~h}$ post-injection. Error bars indicate the s.d. ( $n=4$ mice per group). ${ }^{\star} P<0.05$; NS not significant; two-sided Student's $t$ test. For detailed statistical analysis see Supplementary Tables 6 and 7. c Elimination kinetics of L3.3 and D3.3 in plasma. The concentration-time profiles of L3.3 and D3.3 in plasma (b) fit the first-order elimination. The fitting equation for L3.3 and D3.3 groups is $y=1.396-0.0211 x\left(r^{2}=0.992\right)$ and $y=1.43758-0.0203 x\left(r^{2}=\right.$ 0.989), respectively. $\mathbf{d}$ Hematological parameters, including red blood cells (RBC), hemoglobin (HGB), platelets (PLT), and white blood cells (WBC) of the KM mice after treatment with L3.3 or D3.3 for $6 \mathrm{~h}, 12 \mathrm{~h}, 24 \mathrm{~h}$, and $48 \mathrm{~h}$. The shadow regions represent the normal range of control groups. Error bars indicate the s.d. ( $n=3$ mice per group). For detailed statistical analysis see Supplementary Table 6. e H\&E staining assays of the heart, liver, spleen, lung, and kidney from all experimental groups ( $n=2$ mice per group). Scale bars, $100 \mu \mathrm{m}$. Source data are provided as a Source Data file.

$\mathrm{H} \& \mathrm{E}$ staining after $48 \mathrm{~h}$ injection of $\mathrm{L} 3.3$ or D3.3 reveals that neither noticeable organ damage nor inflammation is distinguished (Fig. 4e). In sum, at least partially if not all, the in vivo administration of L3.3 and D3.3 is safe under the current dose.

Rescuing memory deficits in AD model mice. The high inhibition effect of L3.3 and D3.3 on $A \beta$ aggregation and $A \beta$ mediated cellular toxicity, in addition to their good BBB permeability and biocompatibility, encourage us to investigate in vivo therapeutic efficiency for AD. APPswe/PS1-dE9 [(amyloid precursor protein/presenilin protein 1 (APP/PS1)] double-transgenic mouse model, which is characteristic of $A \beta$ plaque deposition, gliosis, and cognitive impairment ${ }^{46}$, is adopted to check in vivo therapeutic efficiency of chiral Au NPs for AD. The model mice were weekly intravenously administrated for 4 weeks with L3.3 or D3.3. Subsequently, the spatial cognition and memory of the model mice were assessed using the Morris water maze (MWM) test. The latency of different group mice for searching the hidden platform was measured daily for 5 days (Fig. 5a), and the probe trial was conducted after removal of the hidden platform on the 6 th day (Fig. 5b-d). Compared with the wild-type (WT) mice, the AD model mice show the obvious deficits, as evidenced by longer escape latency time (Fig. 5a), shorter time spent in the target quadrant after removal of the platform (Fig. 5b), less platform crossing (Fig. 5c) and more random motion paths (Fig. 5d). 

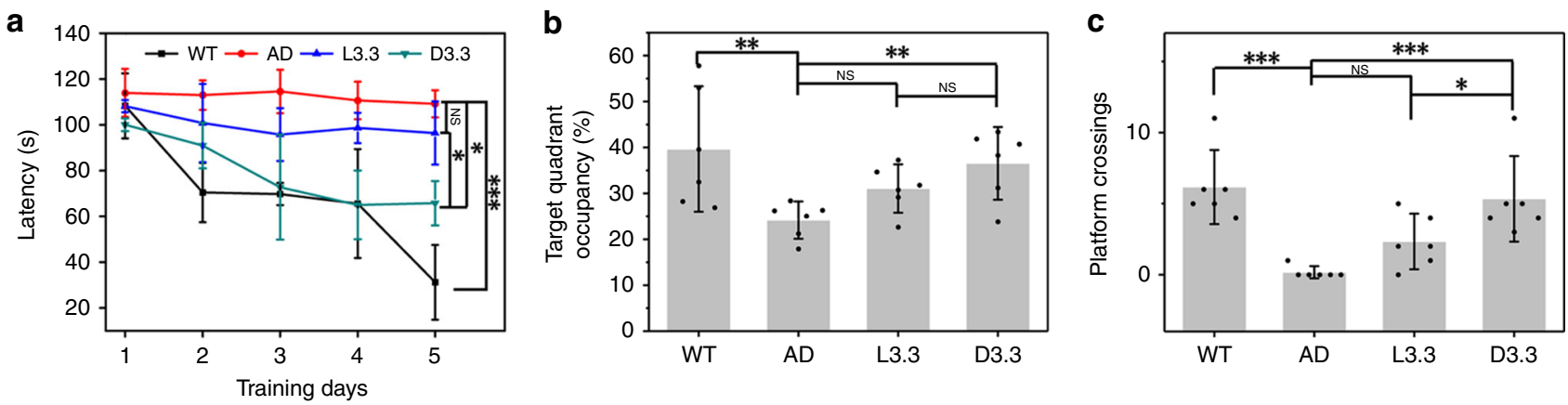

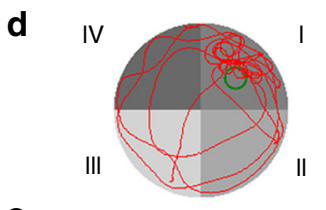

e
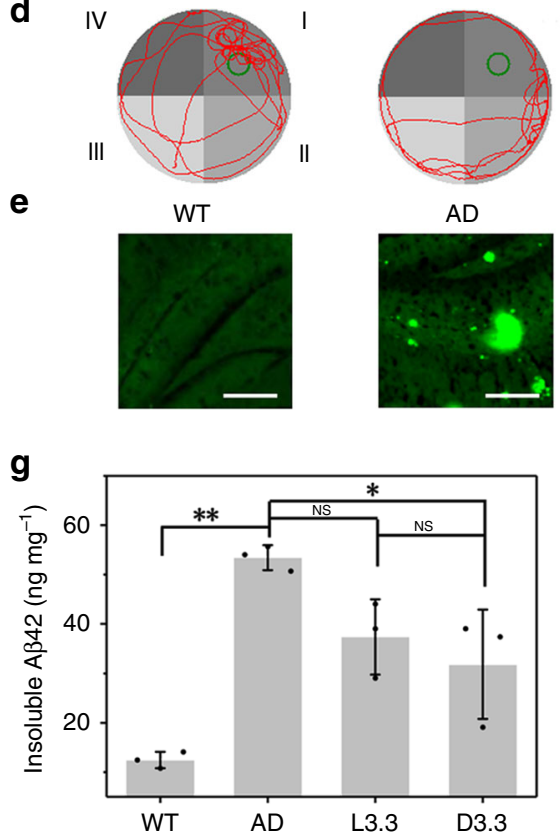

$\mathrm{AD}$

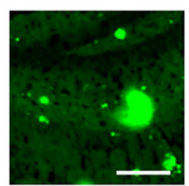

\section{h}

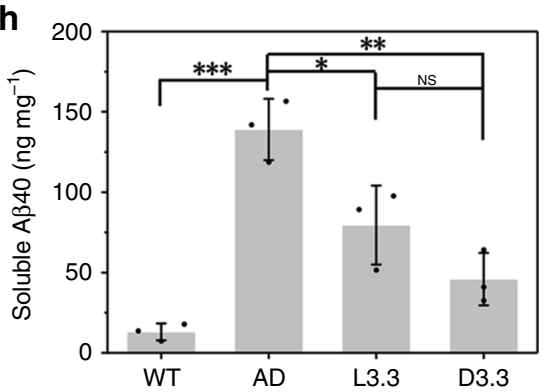

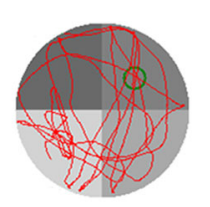

L3.3

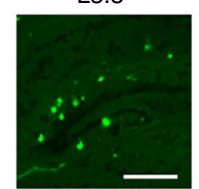

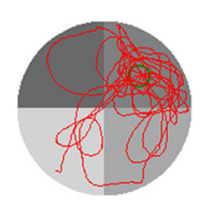

D3.3

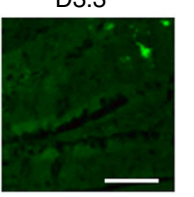

L3.3

$\mathbf{f}$
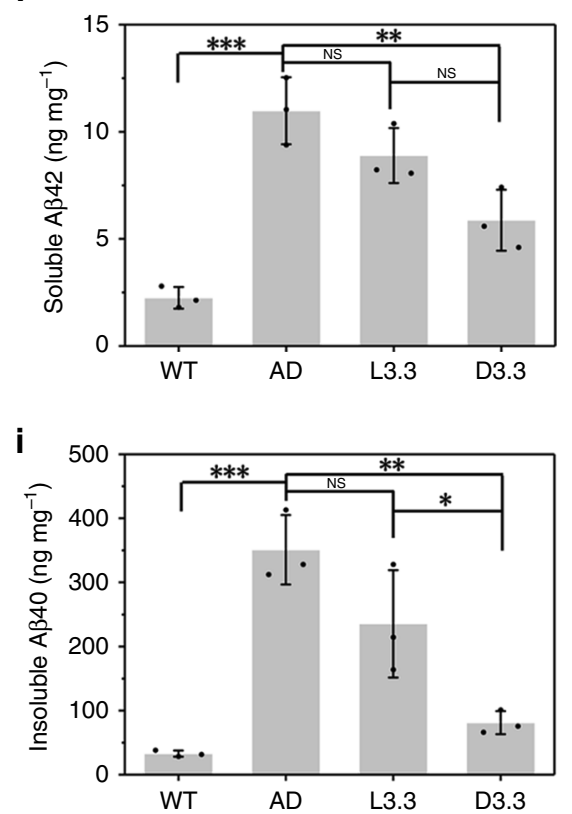

Fig. 5 Effect of L3.3 and D3.3 on rescuing memory impairments in AD model mice. a Latency for escape to platform in the training phase. b Percentage $(\%)$ of time spent in the target quadrant in probe test. c Number of crossing platform time in probe test. Error bars indicate the s.d. ( $n=6$ mice per group). ${ }^{\star} P<0.05 ;{ }^{\star \star} P<0.01 ;{ }^{\star \star \star} P<0.001$; NS not significant; one-way ANOVA, followed by Holm-Sidak post hoc test. For detailed statistical analysis see Supplementary Tables 6 and 7. d Track of probe test. e Immunofluorescence for $A \beta$ in the hippocampus of WT control mice, $A D$ control mice, AD mice with L3.3 or D3.3 treatment. Scale bars, $200 \mu \mathrm{m}$. f-i Soluble $A \beta 42(\mathbf{f})$, insoluble $A \beta 42(\mathbf{g}$ ), soluble $A \beta 40$ (h), and insoluble $A \beta 40$ (i) in the brains measured by ELISA. Error bars indicate the s.d. ( $n=3$ mice per group). ${ }^{\star} P<0.05 ;{ }^{\star \star} P<0.01$; ${ }^{\star \star \star} P<0.001$; NS not significant; one-way ANOVA, followed by HolmSidak post hoc test. For detailed statistical analysis see Supplementary Tables 6 and 7. Source data are provided as a Source Data file.

During the 5-day training and subsequent probe trial, the animals treated with D3.3 display remarkable improvement in spatial learning and memory in comparison with AD model mice, while L3.3 treatment does not cause significant improvement (Fig. 5a-d and Supplementary Movie 1-8). Specifically, the animals administrated with D3.3 exhibit shorter latency to escape onto the platform, slightly longer swimming time at the platform location, more platform crossing and better-focused search strategies for the platform in the quadrant compared with those treated with L3.3 (Fig. 5a-d).

After the MWM test, the mice were killed and the immunofluorescence analysis was carried out to evaluate the ability of L3.3 and D3.3 on reducing $\mathrm{A} \beta$ deposition in the brains. A large amount of $\mathrm{A} \beta$ deposition is found in the hippocampus of $\mathrm{AD}$ mice (Fig. 5e). Impressively, both D3.3 and L3.3 treatment decrease $A \beta$ deposition, but D3.3 treatment is more efficient than L3.3 (Fig. 5e). The A $\beta$ level in the hippocampus of mice is further quantitatively measured by an enzyme-linked immune sorbent assay (ELISA) ${ }^{47}$. The amount of soluble and insoluble $\mathrm{A} \beta 42$, as well as $A \beta 40$, are significantly decreased by D3.3 treatment (Fig. 5f-i). Notably, L3.3 treatment leads to a significant difference in the number of soluble $A \beta 40$, but this decrease is not intense enough to cause obvious improvement in the behavior of $\mathrm{AD}$ mice. In addition, during the therapeutic period, the body weight of mice is not significantly affected by various treatments (Supplementary Fig. 17). Histopathology assay proves that no significant difference is detected in pathological signs between the treated group and the control group (Supplementary Fig. 18). Taken together, a 4-week weekly treatment with D3.3 significantly rescues the spatial learning and memory impairments in $\mathrm{AD}$ mice via reducing $\mathrm{A} \beta$ deposition, presenting a promising therapeutic strategy for $\mathrm{AD}$.

\section{Discussion}

We demonstrate the unique advantages of chiral molecule stabilized NPs for AD treatment. Both theory and experiment disclose that compared with pure L- and D-GSH molecules, L- and DGSH stabilized Au NPs show much-improved prevention of A $\beta$ aggregation via adsorption of peptide monomers on their curvature surfaces (Supplementary Figs. 1 and 8), and the NPs with the size of $3-4 \mathrm{~nm}$ possess the best inhibition efficiency and 
protective effect of neurons against $A \beta 42$ aggregates-induced cellular toxicity. In vivo mice experiment via the intravenous injection demonstrates that L3.3 and D3.3 can be transported from the blood circulation into the brain, and D3.3 has higher brain distribution. Most importantly, a 4 -week weekly intravenous administration of D3.3 decreases $A \beta$ plaque deposition in the brain and rescues the memory deficits of $\mathrm{AD}$ mice. It is worth pointing out that regardless of treatment method or rescue effect, our chiral Au NPs with small size exhibit obvious advantage over the current reported NP systems (Supplementary Table 5). In detail, our chiral NPs can cross the BBB through simple intravenous injection. We notice that the currently reported NP systems are either through stereotactic brain injection or intravenous injection with the assistance of cyclosporine A to modulate Pglycoprotein function. The operation of stereotactic brain injection is complicated and the mortality rate is high. Besides, modulating the P-glycoprotein function to improve cerebral uptake has severe adverse effects that include an increased risk for serious infections. The last but not the least, the target quadrant occupancy of D3.3-treated AD mice is closest to that of the WT group among all the reported NPs (up to 94.9\%). The A $\beta$-based drugs suffer failures to date, likely in part because the drugs tested lack sufficient target engagement or have toxic effects. We highly expect that chiral nanomedicine will open a potential era toward the treatment of Alzheimer's disease thanks to their size- and stereo-determined inhibition of peptide or protein aggregation, the capability of crossing the blood-brain barrier, good biosafety and rather rapid clearance from the body.

\footnotetext{
Methods

Materials. A $\beta 42$ was purchased from CS Bio Co (USA). D-GSH ( $\geq 98 \%)$ was bought from GL Biochem., Ltd. (Shanghai, China). L-GSH ( $\geq 98 \%)$, sodium citrate tribasic dehydrate $(\geq 99 \%)$, gold (III) chloride trihydrate $\left(\mathrm{HAuCl}_{4} \cdot 3 \mathrm{H}_{2} \mathrm{O}\right)$, Thioflavin $\mathrm{T}$ (ThT), sodium borohydride $\left(\mathrm{NaBH}_{4}\right), 1,1,1,3,3,3$-hexafluoro-2-propanol (HFIP), $2 \mathrm{M} \mathrm{NaOH}$ aqueous solution, phosphotungstic acid, and $\mathrm{PBS}(\mathrm{pH}=7.4)$ were got from Alfa Aesar. Dimethyl sulfoxide (DMSO) and acetonitrile were purchased from Beijing Chemical Reagent Company. Concentrated hydrochloric acid, concentrated nitric acid, and hydrogen peroxide $\left(\mathrm{H}_{2} \mathrm{O}_{2}\right)$ were of the highest purity and bought from Sigma Aldrich (USA). Standard solution of gold $\left(1 \mathrm{mg} \mathrm{mL}^{-1}\right)$ was obtained from the National Analysis Center for Iron and Steel (China). CCK-8 assay was purchased from Dojindo Molecular Technologies, Inc. (Kumamoto, Japan). TUNEL assay kit and DAPI were obtained from Roche Applied Science (Roche, Mannheim, Germany). Annexin V-FITC/PI staining assay was bought from Beijing Dingguo Changsheng Biotechnology Co., Ltd. (Genview, China). KM mice and C57BL/6 mice (WT mice) were got from Beijing Vital River Laboratory Animal Technology Co., Ltd. (Beijing, China). The APPswe/PS1dE9 transgenic mice (AD mice) were purchased from the Nanjing Biomedical Research Institute of Nanjing University (Nanjing, China). All the animal experiments were approved by an ethical committee of National Center for Nanoscience and Technology, Harbin Institute of Technology and College of Pharmacy of Harbin Medical University. All ethical obligations were complied with. Mice were housed with water and food ad libitum and with $12 \mathrm{~h} / 12 \mathrm{~h}$ light/dark cycle, under standard environmental conditions (temperature and humidity). The $\beta$-amyloid (D3D2N) primary antibody and the anti-mouse Alexa Fluor 488 secondary antibody for immunofluorescence analysis were purchased from Cell Signaling Technology (Beverly, MA, USA). Mouse A $\beta 1$ 42 ELISA Kit (MG2509) and Mouse A $\beta$ ELISA Kit (MG10283) were achieved from the Trust Specialty Zeal Biological Trade Co., Ltd. (USA). All other chemicals and reagents were of analytical grade and used without further purification. Milli-Q water (electrical conductivity $\sim 18 \mathrm{M} \Omega \mathrm{cm}^{-1}$ ) was used to prepare solutions.
}

Instruments. The hydrodynamic diameter and surface charge of as-synthesized $\mathrm{Au}$ NPs were determined by dynamic light scattering (DLS) using a Zetasizer Nano ZS instrument (Malvern Instruments, UK). TEM images were acquired with a Tecnai G2 F20 U-TWIN (FEI Company, USA) and Tecnai G2 20 S-TWIN (FEI Company, USA) under the accelerating voltage of $200 \mathrm{kV}$. UV-vis spectra were recorded on a Hitachi U-3900 spectrophotometer (Hitachi Corportion, Tokyo, Japan). The size of nanoparticles was analyzed using the Nano Measurer 1.2 software. Fourier transform infrared (FTIR) spectra were obtained on a Perkin Elmer Spectrum One spectrometer by using the $\mathrm{KBr}$ disk method. CD spectra were achieved by a Jasco J1500 spectropolarimeter in aqueous solution. The X-ray diffraction (XRD) patterns were recorded on a D/MAX-TTRIII (CBO) instrument with $\mathrm{Cu}$ Ka radiation $(\lambda=$ $1.542 \AA$ ) operating at $50 \mathrm{kV}$ and $300 \mathrm{~mA}$.
Monte Carlo simulation. Monte Carlo simulation was performed under the NVT ensemble, which meant constant particle number, volume, and temperature. The length of the cubic box was $38.7 \mathrm{~nm}$, and the periodic boundary condition was applied in all the three dimensions. The NPs were distributed in the system randomly, and the positions of NPs in the system were fixed. The peptide chains were moved by following pivot, crankshaft, kink-jump, and translation methods ${ }^{48}$. Peptide chains with a number of 1330 were included in the system. In all, $1 \times 10^{4}$ Monte Carlo steps under a thermal condition were firstly performed for relaxation of the peptide chains, $1 \times 10^{6}$ Monte Carlo steps were then performed for the production run, and the last $1 \times 10^{5}$ steps were used for data analysis. The judgment for forming or breaking hydrogen bonds was made before each Monte Carlo move of peptide bead. For each system, 10 samples with different initial coordinates were performed to achieve the average.

Preparation of L3.3 or D3.3. L3.3 or D3.3 was synthesized by the modified Kumar's method ${ }^{29}$. Typically, an aqueous solution of $\mathrm{HAuCl}_{4} \cdot 3 \mathrm{H}_{2} \mathrm{O}(84 \mu \mathrm{L}, 476.3$ $\mathrm{mM})$ was added to $5 \mathrm{~mL}$ fresh L- or D-GSH aqueous solution $(0.12 \mathrm{mmol})$, which was then poured into $36 \mathrm{~mL} \mathrm{H}_{2} \mathrm{O}$. After continuous stirring for half an hour, $2 \mathrm{~mL}$ $\mathrm{NaBH}_{4}$ aqueous solution $(0.88 \mathrm{mmol})$ was added slowly with rapid stirring to fully reduce the gold ions, and then the solution was stirred for another $2 \mathrm{~h}$ until the solution became a brown color. The resultant product was collected by ultrafiltration at $10,620 \times g$ for $15 \mathrm{~min}$ and then washed three times with deionized water to remove free GSH molecules. Finally, the resulting L3.3 or D3.3 was dispersed in aqueous solution and stored at $4{ }^{\circ} \mathrm{C}$ before use in further study.

Preparation of L9 or D9. L9 or D9 was synthesized by the modified method ${ }^{30}$. Typically, an aqueous solution of $\mathrm{HAuCl}_{4} \cdot 3 \mathrm{H}_{2} \mathrm{O}(0.125 \mathrm{~mL}, 476.83 \mathrm{mM})$ was mixed with an aqueous solution of L- or D-GSH $(0.15 \mathrm{mM}, 100 \mathrm{~mL})$. After stirred for half an hour, the $\mathrm{pH}$ value of the solution was tuned to 11.00 using $2 \mathrm{M} \mathrm{NaOH}$ aqueous solution. Afterward, the mixture was kept overnight at $37^{\circ} \mathrm{C}$. The free GSH molecules in solution were removed by centrifugation at $10,620 \times g$ for $15 \mathrm{~min}$, and then the precipitate was dispersed in the aqueous solution before use.

Preparation of L15 or D15. L15 or D15 was synthesized by the modified method ${ }^{30}$ Typically, an aqueous solution of $\mathrm{HAuCl}_{4} \cdot 3 \mathrm{H}_{2} \mathrm{O}(0.125 \mathrm{~mL}, 476.83 \mathrm{mM})$ was mixed with an aqueous solution of L- or D-GSH $(0.15 \mathrm{mM}, 100 \mathrm{~mL})$. After stirred for $3 \mathrm{~min}$, the $\mathrm{pH}$ value of the solution was tuned to 11.00 using $2 \mathrm{M} \mathrm{NaOH}$ aqueous solution. Afterward, the mixture was kept overnight at $37^{\circ} \mathrm{C}$. The free GSH molecules in solution were removed by centrifugation at $10,620 \times g$ for $10 \mathrm{~min}$, and then the precipitate was washed three times and finally dispersed in the aqueous solution before use.

Preparation of C3.5. For comparison, C3.5 was also prepared according to the literature ${ }^{31}$. Typically, an aqueous solution of $\mathrm{HAuCl}_{4} \cdot 3 \mathrm{H}_{2} \mathrm{O}(1 \%, 1 \mathrm{~mL})$ and sodium citrate solution $(0.03 \mathrm{M}, 2 \mathrm{~mL})$ were added to $50 \mathrm{~mL}$ of purified water and stirred. Then freshly prepared $\mathrm{KBH}_{4}$ aqueous solution $(0.1 \mathrm{M}, 1 \mathrm{~mL})$ was added, and the solution color changed from colorless to wine red. The solution was left undisturbed for $2 \mathrm{~h}$. The obtained citrate-capped Au nanoparticles were stored at $4{ }^{\circ} \mathrm{C}$.

Preparation of A $\mathbf{\beta} 42$ solution. In total, $1 \mathrm{mg} \mathrm{A} \beta 42$ peptide was first dissolved in 1 $\mathrm{mL}$ of HFIP and shaken at room temperature for $24 \mathrm{~h}$ in a sealed vial. Afterward, HFIP was removed by evaporation under a gentle stream of nitrogen gas. Subsequently, an aliquot of A $\beta 42$ was redissolved with $120 \mu \mathrm{L}$ of DMSO and diluted in $5.5 \mathrm{~mL}$ of pure water. The final concentration of $\mathrm{A} \beta 42$ was $\sim 40 \mu \mathrm{M}$. The A $\beta 42$ solution was filtered through a $0.22-\mu \mathrm{m}$ filter before injected on a Superdex 200 10/300 GL column (GE HealthCare) equilibrated in PBS buffer ( $10 \mathrm{mM}$, pH 7.4) at a flow rate of $0.5 \mathrm{~mL} \mathrm{~min}{ }^{-1}$. Absorbance at $280 \mathrm{~nm}$ was recorded (Wyatt Technology, CA, USA). The oligomer A11 polyclonal antibody (Thermo Fisher, 1:250 dilution) was used according to the manufacturer's instruction. A $10 \mu \mathrm{L}$ of each sample was applied onto untreated nitrocellulose membranes and allowed to dry. A HRP-conjugated goat anti-rabbit IgG antibody (Invitrogen, Carlsbad, CA, 1:3000 dilution) was used to detect bound A11 antibodies using a chemiluminescence with the Clarity ${ }^{\text {Ts }}$ ECL Western Blotting Substrate (Bio-Rad).

Fibrillation experiments. The fibrillation of $\mathrm{A} \beta 42(40 \mu \mathrm{M})$ in the absence and presence of various types of Au NPs were incubated at $37^{\circ} \mathrm{C}$ in a shaker. The concentration of L3.3/D3.3, L9/D9, and L15/D15 were $110 \mathrm{nM}, 15 \mathrm{nM}$, and $5 \mathrm{nM}$, respectively, to keep the same surface area in each group. The A $\beta 42$ fibrillation process was monitored by ThT fluorescence and CD spectroscopy at specific time points.

ThT fluorescence assay. The mixture solution of $100 \mu \mathrm{L}$ A $\beta 42$ sample and ThT solution $(10 \mu \mathrm{L}$ and $20 \mu \mathrm{M})$ was incubated in a 96-well plate at room temperature for $15 \mathrm{~min}$. Fluorescence was measured with the microplate reader (EL800, Bio-Tek Instrument, USA). Excitation and emission wavelengths were 450 and $482 \mathrm{~nm}$, respectively. The experiments were performed in triplicate. 
CD studies and secondary structure analysis. CD spectra were employed for investigating the inhibition effect of chiral Au NPs on A $\beta 42$ fibrillization, which were recorded by the Jasco J-1500 spectropolarimeter (Jasco Co. Ltd., Tokyo, Japan). The experiments were performed by infusing a $200-\mu \mathrm{L}$ sample into a quartz cell with a path length of $1 \mathrm{~mm}$. The experimental parameter was set as follows:

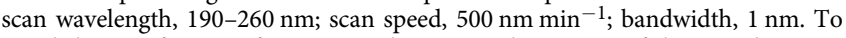
avoid the interference of GSH-coated Au NPs, the spectra of the mixed Au NPs and $A \beta 42$ samples were collected using the CD spectra of GSH-coated Au NPs alone as the baseline. It should be noted that in the CD experiments, the solubilizing assistant DMSO for $\mathrm{A} \beta 42$ was replaced by acetonitrile. The protein secondary structure was analyzed using the CDPro software.

TEM characterization. To prepare the TEM specimen, a $10 \mu \mathrm{L}$ sample was dropped onto a carbon-coated 300-mesh copper grid. After $15 \mathrm{~min}$, the remaining solution was soaked up from the edge of the grid using filter paper. Afterward, the specimen was stained with $10 \mu \mathrm{L}$ of $1.5 \%(\mathrm{w} / \mathrm{v})$ phosphotungstic acid solution $(\mathrm{pH}$ $=7.4$ ) for $2 \mathrm{~min}$, and then the staining solution was drawn away from the edge of the grid with filter paper. The grid was washed with $10 \mu \mathrm{L}$ of deionized water three times and dried at room temperature. Finally, the sample was observed using Tecnai G2 20 S-TWIN (FEI Company, USA) under the accelerating voltage of $200 \mathrm{kV}$.

AFM imaging. AFM morphology images were recorded using Multimode-8 AFM (Bruker, USA). To prepare a specimen for AFM, a $10 \mu \mathrm{L}$ sample was deposited onto freshly cleaved mica surface for $10 \mathrm{~min}$. The sample was then briefly rinsed with Milli-Q water and dried with a gentle stream of nitrogen gas. All morphology images were recorded using an intelligent mode with a $512 \times 512$ pixel resolution and a scan speed of $1.0-1.5 \mathrm{~Hz}$. Analysis of the images was carried out using the NanoScope Analysis 1.40 Software.

\section{ITC measurements. ITC experiment was performed in a MicroCal ITC200} instrument (Malvern, Sweden) at $25^{\circ} \mathrm{C}$ and the stirring speed was set to $750 \mathrm{rpm}$. In the ITC experiment, $40 \mu \mathrm{L}$ of $\mathrm{A} \beta 42$ solution $(138 \mu \mathrm{M})$ was injected in each step of $2 \mu \mathrm{L}$ into $200 \mu \mathrm{L}$ of L3.3/D3.3 solution $(1.5 \mu \mathrm{M})$. The experimental thermogram was fitted to a one-site binding model implemented in the instrument software supplied by the manufacturer.

DFT computation and molecular docking. The $(1 \times 3)$ supercell model with a three-layered periodic slab separated by a vacuum region of $15 \AA$ was used to model the Au (111) surface and its interaction with ligands (L-GSH or D-GSH). All calculations were performed using the Vienna ab initio simulation package (VASP) with plane-wave pseudopotential method ${ }^{39}$. The electronic exchange and correlation effects were described by the Perdew-Burke-Ernzerhof (PBE) functional ${ }^{40}$ with the generalized gradient approximation (GGA) and the core electrons were described by the full-potential projector augmented wave (PAW) $\operatorname{method}^{41}$. An energy cutoff of $400 \mathrm{eV}$ for the plane-wave expansion was used and the force on the relaxed atoms was $<-0.03 \mathrm{eV} \AA^{-1}$. The spin-polarization was taken into account in all calculations. The Brillouin zone was sampled by $(1 \times 3 \times 1)$ k-point grid generated within the Monkhorst-Pack scheme.

The molecular docking simulation was carried out by using Auto-Dock 4.2.6 and AutoDockTools 1.5.6 was employed to generate the docking input files and analyze the docking results ${ }^{42}$. To identify potential binding sites of $A \beta 17-36$ on Lor D-GSH stabilized Au (111), a big grid box size of $126 \times 126 \times 126$ points with a large spacing of $0.603 \AA$ between the grid points was implemented and the grid box was large enough to cover the entire surface of $\mathrm{Au}$ (111). The ones with the lowest binding energy were selected for detailed analysis and further studies. The affinity map of the adsorbed ligand on $\mathrm{Au}$ (111) and the peptide was calculated using Auto Grid. Lamarckian Genetic Algorithm (LGA) added a local minimization to the genetic algorithm, enabling modification of the gene population. The docking parameter was as follows: trials of 100 dockings, the population size of 150 , the random starting position and conformation, the mutation rate of 0.02 , the cross overrate of 0.8 , the local search rate of 0.06 , and 25 million energy evaluations. Final docked conformation was clustered using a tolerance of $2.0 \AA$ root-meansquare deviations (RMSD).

Cell viability assay. To verify that the L3.3 or D3.3 could decrease the cell mortality induced by A $\beta$ aggregation, SH-SY5Y cells were plated at a concentration of $1.0 \times 10^{4}$ cells well ${ }^{-1}$ in 96 -well plates with $200 \mu \mathrm{L}$ of media and incubated overnight. A 342 monomers $(40 \mu \mathrm{M})$ alone or together with L3.3 or D3.3 (110 nM) were dispensed into the SH-SY5Y cells, and the cells were further incubated for $48 \mathrm{~h}$ at $37^{\circ} \mathrm{C}$ and in $5 \% \mathrm{CO}_{2}$ incubator. Cells were treated with the same amount of PBS as a control. Cytotoxicity was measured by using a CCK- 8 assay. A $10 \mu \mathrm{L}$ of CCK- 8 solution was added to each well and the absorbance at $450 \mathrm{~nm}$ was measured after $1 \mathrm{~h}$ of incubation using a microplate reader (EL800, Bio-Tek Instrument, USA). To further investigate the cytotoxicity of L3.3 and D3.3, the various concentration of L3.3 or D3.3 was dispensed into the SH-SY5Y cells, and further incubated for $48 \mathrm{~h}$ at $37^{\circ} \mathrm{C}$ and in $5 \% \mathrm{CO}_{2}$ incubator. Cytotoxicity was measured using a CCK-8 assay.
TUNEL-DAPI co-staining assay. DNA fragmentation induced by A $\beta 42$ fibers was examined by using an in situ cell death detection kit following the manufacturer's protocol. Briefly, cells were cultured with $\mathrm{A} \beta 42$ peptides $(40 \mu \mathrm{M})$ and L3.3/D3.3 $(110 \mathrm{nM})$ at $37^{\circ} \mathrm{C}$ for $48 \mathrm{~h}$, meanwhile, cells were treated with $40 \mu \mathrm{M}$ of $\mathrm{A} \beta 42$ or the same amount of PBS buffer as a control. After that, cells in chamber slides were fixed with $4 \%$ formaldehyde for $15 \mathrm{~min}$ and permeabilized with $0.1 \%$ Triton X-100 in PBS. The cells were cultured with TUNEL reaction mixture for $1 \mathrm{~h}$. For nuclear staining, cells were incubated with $1 \mu \mathrm{g} \mathrm{mL}-1$ of DAPI for $10 \mathrm{~min}$ at $37^{\circ} \mathrm{C}$. At the end of incubation, the cells were rinsed with PBS and the images were captured using a laser confocal microscope (Zeiss 710, Zeiss, Oberkochen, Germany).

Flow cytometry analysis. The externalization of phosphatidylserine to the cell surface was detected by flow cytometry using a double-staining with Annexin VFITC and PI. The same cell lines were cultivated in similar conditions for TUNEL staining. After $48 \mathrm{~h}$, cells were harvested by trypsinization and adjusted at $2.0 \times 10^{5}$ cells $\mathrm{mL}^{-1}$ with combining buffer. The cell suspension was then incubated with $5 \mu \mathrm{L}$ of $5 \mu \mathrm{M}$ Annexin V-FITC solution and $10 \mu \mathrm{L}$ of $20 \mu \mathrm{g} \mathrm{mL}^{-1}$ PI solution at room temperature in the dark for $15 \mathrm{~min}$. Data acquisition was then performed by a NovoCyte flow cytometer (ACEA Biosciences, Inc., San Diego, USA) using NovoExpress 1.0.2 software.

Biodistribution and toxicity evaluation in vivo. Healthy $\mathrm{KM}$ mice $(n=18)$ were intravenously injected with D3.3 and L3.3 at a dose of $25 \mathrm{mg} \mathrm{kg}^{-1}$, respectively. For in vivo biodistribution evaluation, at the indicated time points, the healthy mice were euthanized $(n=4)$. The blood and major organs including the brain, liver, kidney, and spleen were collected and digested with the help of aqua regia and hot temperature to analyze the amount of $\mathrm{Au}$ by inductively coupled plasma mass spectrometry (NexION 300X, Perkin Elmer, USA). At the same time points, $20 \mu \mathrm{L}$ of blood was collected to perform blood panel analysis (HF-3800, HANFANG Ltd. Jinan, China). At $48 \mathrm{~h}$ after injection, major organs including heart, liver, spleen, lung, and kidney $(n=2)$ were collected for investigating the histopathology change after H\&E staining. The sections were observed, and photos were taken using an inverted phase contrast microscope (AMEX1200, Life Technologies, WA, USA).

MWM test. The C57BL/6 mice were regarded as WT mice. The AD mice were divided into three groups, $\mathrm{AD}$ group and two sample groups $(n=6)$. All mice were male, and 5-month-old, which were administered with PBS, L3.3 and D3.3 (25 mg $\left.\mathrm{kg}^{-1}\right)$, respectively, every week for 4 weeks. All mice were trained and tested in a water maze with a diameter of $1.2 \mathrm{~m}$ (RD1101-MWM-G, Shanghai Mobiledatum Information Technology Co., Ltd, China). The maze was filled with water and drained every 2 days. The temperature of the water was maintained at $22 \pm 1{ }^{\circ} \mathrm{C}$. Before the task, the water was dyed with titanium dioxide. The platform $(0.1 \mathrm{~m}$ in diameter) was immobilized to $2 \mathrm{~cm}$ under the water surface during the training period. The maze contained a mass of fixed visual cues on the walls. The performance of each mouse was recorded with a video-tracking system. In the first 5 days, the mice received three acquisition trials daily. Briefly, three starting points, excluding the one quadrant with a platform, were randomly selected in three daily trials. Each mouse facing the wall of the tank was set free into the water. If the mouse found the hidden platform successfully within $120 \mathrm{~s}$, it was allowed to stay on the platform for $30 \mathrm{~s}$. If the mouse failed to reach the platform within $120 \mathrm{~s}$, it was guided to stay on the platform for $30 \mathrm{~s}$. Upon completion of the daily three trials, mice were removed from the maze, towel dried, and then returned to the cages. On the 6th day, the spatial memory of each mouse was explored by a probe trial without the platform. Every trained mouse was released into the water at the right opposite position of the escape platform and was allowed to swim freely for $120 \mathrm{~s}$. The time that each mouse spent in searching for the platform in the quadrant where the platform used to be (target quadrant), and the number of times that each mouse crossed the platform were recorded.

Immunofluorescence staining. After the MWM test, the mice were killed via cardiac perfusion with $0.9 \%$ saline, and their brains were fixed in $4 \%$ paraformaldehyde. The brain was then placed in 15 and 30\% sucrose solution, followed by being cut into $30 \mu \mathrm{m}$ slices using a low temperature thermostat (Leica, Germany). Each section was incubated with $10 \%$ normal sera, followed by overnight incubation with the D3D2N primary antibody (1:200 dilution) at $4{ }^{\circ} \mathrm{C}$. Then, sections were incubated with the anti-mouse Alexa Fluor 488 secondary antibody (1:200 dilution) for $1.5 \mathrm{~h}$ at room temperature. Finally, the brain sections were imaged using an Olympus microscope with a BX51 digital camera (Olympus, Japan).

\section{Measurement of soluble and insoluble $A \beta 42$ as well as A $\beta 40$ in the brain}

Brain tissue (half of one brain, three mice per group) for ELISAs were mechanically homogenized in $10 \mathrm{vol}$ of ice-cold guanidine buffer $(\mathrm{pH}=8.0)$ and mixed for 3-4 $\mathrm{h}$ at room temperature as described ${ }^{48}$. Then the diluted brain homogenate with 1:10 by ice-cold casein buffer $\left(0.25 \%\right.$ casein, $0.05 \%$ sodium azide, $20 \mu \mathrm{g} \mathrm{mL}^{-1}$ aprotinin, $5 \mathrm{mM}$ EDTA, $10 \mu \mathrm{g} \mathrm{mL}^{-1}$ leupeptin, and $\mathrm{pH}$ 8.0) was centrifuged under $25,660 \times g$ at $4{ }^{\circ} \mathrm{C}$ for $30 \mathrm{~min}$ (Auanti J-26XP, Bechman Coulter Inc., Fullerton, USA). The supernatant was removed for ELISA measurement of soluble A $\beta 42$ and A $\beta 40$ without further dilution. The homogenate pellet that remained after centrifugation 
was added to $440 \mu \mathrm{L}$ cold formic acid and the tube was kept in ice. Each sample was sonicated in ice continuously until the pellet dissolved. Then high-speed centrifugation at $28,450 \times g$ for $1 \mathrm{~h}$ at $4^{\circ} \mathrm{C}$ was performed (Allegra 64R, Bechman Coulter Inc., San Diego, USA). Afterward, $105 \mu \mathrm{L}$ supernatant was diluted into $2 \mathrm{~mL}$ of formic-acid neutralization buffer $\left(1 \mathrm{M}\right.$ Tris base $/ 0.5 \mathrm{M} \mathrm{Na}_{2} \mathrm{HPO}_{4} / 0.05 \%$ sodium azide) immersed in ice for ELISA measurement of insoluble $\mathrm{A} \beta 42$ and A $\beta 40$. Mouse A $\beta 1-42$ ELISA Kit (MG2509) and Mouse A $\beta$ ELISA Kit (MG10283) were used following the manufacturer's protocol.

Statistical analysis. All the data were presented with the mean \pm standard deviation (s.d.) and were analyzed using SPSS 19.0 statistical analysis software (SPSS, Chicago, IL, USA). A two-sided Student's $t$ test was used to assess the difference between the two groups. Difference among multiple groups was analyzed via one-way analysis of variance (ANOVA), followed by Holm-Sidak post hoc test with ${ }^{* * *} P<0.001,{ }^{* *} P<0.01,{ }^{*} P<0.05$.

Reporting summary. Further information on research design is available in the Nature Research Reporting Summary linked to this article.

\section{Data availability}

The source data underlying Figs. 1-5, Supplementary Figs. 1-12, and Supplementary Figs. 14-17 are provided as Source Data file with this paper. Any other data are available from the corresponding author upon reasonable request. Source data are provided with this paper. Source data are provided with this paper.

Received: 2 July 2019; Accepted: 27 August 2020;

Published online: 22 September 2020

\section{References}

1. Patterson, C. World Alzheimer Report 2018-The State Of The Art Of Dementia Research: New Frontiers. (Alzheimer's Disease International (ADI), London, UK, 2018).

2. Wang, J., Gu, B. J., Masters, C. L. \& Wang, Y. J. A systemic view wof Alzheimer disease-insights from amyloid-beta metabolism beyond the brain. Nat. Rev. Neurol. 13, 612-623 (2017).

3. Barnham, K. J. \& Bush, A. I. Biological metals and metal-targeting compounds in major neurodegenerative diseases. Chem. Soc. Rev. 43, 6727-6749 (2014).

4. Barnham, K. J., Masters, C. L. \& Bush, A. I. Neurodegenerative diseases and oxidative stress. Nat. Rev. Drug Discov. 3, 205-214 (2004).

5. Shi, Y. \& Holtzman, D. M. Interplay between innate immunity and Alzheimer disease: APOE and TREM2 in the spotlight. Nat. Rev. Immunol. 18, 759-772 (2018).

6. Eisenberg, D. \& Jucker, M. The amyloid state of proteins in human diseases. Cell 148, 1188-1203 (2012).

7. Jakob-Roetne, R. \& Jacobsen, H. Alzheimer's disease: from pathology to therapeutic approaches. Angew. Chem. Int. Ed. 48, 3030-3059 (2009)

8. Doig, A. J. \& Derreumaux, P. Inhibition of protein aggregation and amyloid formation by small molecules. Curr. Opin. Struct. Biol. 30, 50-56 (2015).

9. Soto, C. et al. $\beta$-sheet breaker peptides inhibit fibrillogenesis in a rat brain model of amyloidosis: Implications for Alzheimer's therapy. Nat. Med. 4, 822-826 (1998).

10. Schneider, L. S. et al. Clinical trials and late-stage drug development for Alzheimer's disease: an appraisal from 1984 to 2014. J. Intern. Med. 275, 251-283 (2014).

11. Karran, E., Mercken, M. \& Strooper, B. D. The amyloid cascade hypothesis for Alzheimer's disease: an appraisal for the development of therapeutics. Nat. Rev. Drug Discov. 10, 698-712 (2011).

12. Linse, S. et al. Nucleation of protein fibrillation by nanoparticles. Proc. Natl Acad. Sci. USA 104, 8691-8696 (2007)

13. Kim, Y., Park, J.-H., Lee, H. \& Nam, J.-M. How do the size, charge and shape of nanoparticles affect amyloid beta aggregation on brain lipid bilayer? Sci. Rep. 6, 19548 (2016).

14. Liao, Y. H. et al. Negatively charged gold nanoparticles inhibit Alzheimer's amyloid- $\beta$ fibrillization, induce fibril dissociation, and mitigate neurotoxicity. Small 8, 3631-3639 (2012)

15. Cabaleiro-Lago, C. et al. Inhibition of amyloid beta protein fibrillation by polymeric nanoparticles. J. Am. Chem. Soc. 130, 15437-15443 (2008).

16. Skaat, H., Chen, R., Grinberg, I. \& Margel, S. Engineered polymer nanoparticles containing hydrophobic dipeptide for inhibition of amyloid- $\beta$ fibrillation. Biomacromolecules 13, 2662-2670 (2012).

17. Zhang, J. et al. Epigallocatechin-3-gallate (EGCG)-stabilized selenium nanoparticles coated with Tet-1 peptide to reduce amyloid- $\beta$ aggregation and cytotoxicity. ACS Appl. Mater. Interfaces 6, 8475-8487 (2014).
18. Dreaden, E. C. et al. The golden age: gold nanoparticles for biomedicine. Chem. Soc. Rev. 41, 2740-2779 (2012).

19. Shilo, M. et al. The effect of nanoparticle size on the probability to cross the blood-brain barrier: an in-vitro endothelial cell model. J. Nanobiotechnol. 13, 1-7 (2015).

20. Xiong, N. et al. Design of a molecular hybrid of dual peptide inhibitors coupled on AuNPs for enhanced inhibition of amyloid $\beta$-protein aggregation and cytotoxicity. Small 13, 1601666 (2017).

21. Pocernich, C. B. \& Butterfield, D. A. Elevation of glutathione as a therapeutic strategy in Alzheimer disease. Biochim. Biophys. Acta 1822, 625-630 (2012).

22. Smeyne, M. \& Smeyne, R. J. Glutathione metabolism and Parkinson's disease Free Radic. Biol. Med. 62, 13-25 (2013).

23. Geldenhuys, W. et al. Brain-targeted delivery of paclitaxel using glutathionecoated nanoparticles for brain cancers. J. Drug Target. 19, 837-845 (2011)

24. Qing, G. et al. Chiral effect at protein/graphene interface: a bioinspired perspective to understand amyloid formation. J. Am. Chem. Soc. 136, 10736-10742 (2014)

25. Guan, Y. et al. Stereochemistry and amyloid inhibition: asymmetric triplex metallohelices enantioselectively bind to A $\beta$ peptide. Sci. Adv. 4, eaao6718 (2018).

26. Gao, G. et al. The size-effect of gold nanoparticles and nanoclusters in the inhibition of amyloid-beta fibrillation. Nanoscale 9, 4107-4113 (2017).

27. Shaw, C. P., Middleton, D. A., Volk, M. \& Lévy, R. Amyloid-derived peptide forms self-assembled monolayers on gold nanoparticle with a curvaturedependent $\beta$-sheet structure. ACS Nano 6, 1416-1426 (2012).

28. Auer, S., Trovato, A. \& Vendruscolo, M. A Condensation-ordering mechanism in nanoparticle-catalyzed peptide aggregation. PLoS Comput. Biol. 5, e1000458 (2009).

29. Kumar, A. et al. Neuropilin-1-targeted gold nanoparticles enhance therapeutic efficacy of platinum(IV) drug for prostate cancer treatment. ACS Nano 8 , 4205-4220 (2014)

30. Mao, X., Li, Z. P. \& Tang, Z. Y. One pot synthesis of monodispersed Lglutathione stabilized gold nanoparticles for the detection of $\mathrm{Pb}^{2+}$ ions. Front. Mater. Sci. 5, 322-328 (2011).

31. Yan, W. et al. A super highly sensitive glucose biosensor based on Au nanoparticles-AgCl@polyaniline hybrid material. Biosens. Bioelectron. 23, 925-931 (2008).

32. Jan, A., Gokce, O., Luthi-Carter, R. \& Lashuel, H. A. The ratio of monomeric to aggregated forms of $A \beta 40$ and $A \beta 42$ is an important determinant of amyloid- $\beta$ aggregation, fibrillogenesis, and toxicity. J. Biol. Chem. 283, 28176-28189 (2008)

33. Streich, C. et al. Characterizing the effect of multivalent conjugates composed of $A \beta$-specific ligands and metal nanoparticles on neurotoxic fibrillar aggregation. ACS Nano 10, 7582-7597 (2016).

34. Sreerama, N. \& Woody, R. W. Estimation of protein secondary structure from circular dichroism spectra: Comparison of CONTIN, SELCON, and CDSSTR methods with an expanded reference set. Anal. Biochem. 287, 252-260 (2000).

35. Ahmed, M. et al. Structural conversion of neurotoxic amyloid- $\beta 1-42$ oligomers to fibrils. Nat. Struct. Mol. Biol. 17, 561-567 (2010).

36. Gao, N. et al. Transition-metal-substituted polyoxometalate derivatives as functional anti-amyloid agents for Alzheimer's disease. Nat. Commun. 5, 3422 (2014).

37. Goy-López, S. et al. Physicochemical characteristics of protein-NP bioconjugates: the role of particle curvature and solution conditions on human serum albumin conformation and fibrillogenesis inhibition. Langmuir 28, 9113-9126 (2012)

38. Spencer, R. K., Li, H. \& Nowick, J. S. X-ray crystallographic structures of trimers and higher-order oligomeric assemblies of a peptide derived from Aß17-36. J. Am. Chem. Soc. 136, 5595-5598 (2014)

39. Kresse, G. \& Furthmüller, J. Efficient iterative schemes for ab initio totalenergy calculations using a plane-wave basis set. Phys. Rev. B 54, 11169-11186 (1996).

40. Perdew, J. P., Burke, K. \& Ernzerhof, M. Generalized gradient approximation made simple. Phys. Rev. Lett. 77, 3865-3868 (1996).

41. Blöchl, P. E. Projector augmented-wave method. Phys. Rev. B 50, 17953-17979 (1994).

42. Morris, G. M. et al. AutoDock4 and AutoDockTools4: automated docking with selective receptor flexibility. J. Comput. Chem. 30, 2785-2791 (2009).

43. Cao, Q. et al. Inhibiting amyloid- $\beta$ cytotoxicity through its interaction with the cell surface receptor LilrB2 by structure-based design. Nat. Chem. 10, 1213-1221 (2018)

44. Chang, K. L., Pee, H. N., Yang, S. \& Ho, P. C. Influence of drug transporters and stereoselectivity on the brain penetration of pioglitazone as a potential medicine against Alzheimer's disease. Sci. Rep. 5, 9000 (2015).

45. Sela, H. et al. Spontaneous penetration of gold nanoparticles through the blood brain barrier (BBB). J. Nanobiotechnol. 13, 71 (2015).

46. Drummond, E. \& Wisniewski, T. Alzheimer's disease: experimental models and reality. Acta Neuropathol. 133, 155-175 (2017). 
47. Johnson-Wood, K. et al. Amyloid precursor protein processing and A $\beta 42$ deposition in a transgenic mouse model of Alzheimer disease. Proc. Natl Acad. Sci. USA 94, 1550-1555 (1997).

48. Zhang, R. et al. Physical gelation of polypeptide-polyelectrolyte-polypeptide (ABA) copolymer in solution. Macromolecules 45, 6201-6209 (2012).

\section{Acknowledgements}

This work was supported financially by the National Key Basic Research Program of China (grant no. 2014CB931801 and 2016YFA0200700), National Natural Science Foundation of China (grant no. 21890381, 21721002 and 21475029), Frontier Science Key Project of Chinese Academy of Sciences (grant no. QYZDJ-SSW-SLH038), K. C. Wong Education Foundation, and National Science Fund for Distinguished Young Scholars (grant no. 51825202). The authors thank National Center for Protein Sciences at Peking University in Beijing, China, for assistance with ITC experiment and Dr. Hui Li for help with collecting data.

\section{Author contributions}

K.H., S.L., and Z.T. conceived the idea for this study. K.H. synthesized the samples and participated in characterization, modeling, and cell and animal experiments. J.L. participated in AFM characterization. D.W. participated in TEM characterization. K.H., H.W., and K.W. conducted the DFT computation and molecular docking. K.H., B.L., and X.S. carried out the Monte Carlo simulation. K.H., Q.H., and H.Y.W. performed the cell viability assay. K.H. and J.Z. performed the biodistribution and toxicity evaluation in vivo experiment. K.H., K.L., and J.A. carried out the MWM experiment and immunofluorescence staining. S.L. and Z.T. supervised the project. K.H., S.L., and Z.T. wrote the manuscript. Q.C. helped revise the manuscript. All authors commented on the data and the manuscript.

\section{Competing interests}

The authors declare no competing interests.

\section{Additional information}

Supplementary information is available for this paper at https://doi.org/10.1038/s41467020-18525-2.

Correspondence and requests for materials should be addressed to S.L. or Z.T.

Peer review information Nature Communications thanks the anonymous reviewer(s) for their contribution to the peer review of this work. Peer reviewer reports are available.

Reprints and permission information is available at http://www.nature.com/reprints

Publisher's note Springer Nature remains neutral with regard to jurisdictional claims in published maps and institutional affiliations.

(c) (i) Open Access This article is licensed under a Creative Commons Attribution 4.0 International License, which permits use, sharing adaptation, distribution and reproduction in any medium or format, as long as you give appropriate credit to the original author(s) and the source, provide a link to the Creative Commons license, and indicate if changes were made. The images or other third party material in this article are included in the article's Creative Commons license, unless indicated otherwise in a credit line to the material. If material is not included in the article's Creative Commons license and your intended use is not permitted by statutory regulation or exceeds the permitted use, you will need to obtain permission directly from the copyright holder. To view a copy of this license, visit http://creativecommons.org/ licenses/by/4.0/.

(C) The Author(s) 2020 